Artigos originais

Economia e Sociedade, Campinas, Unicamp. IE.

http://dx.doi.org/10.1590/1982-3533.2020v29n1art04

\title{
Densidade, distância, divisão e as redes de produção globais: o caso do setor brasileiro de petróleo e gás *
}

\author{
Sören Scholvin * \\ Maurício Serra ${ }^{* * *}$ \\ Mariane Françoso ${ }^{* * * *}, * * * * *$ \\ Paula Bastos \\ Patrícia Mello \\ Adriano Borges ${ }^{* * * * * * * * * * * * * * * * * *}$
}

\section{Resumo}

Além de fomentar o aumento do comércio entre países, a globalização tem mudado significativamente os processos econômicos ao possibilitar que as empresas dividam as cadeias de produção e comercialização em vários segmentos, que se espalham por todo o mundo. Nesse sentido, as redes de produção globais (RPGs), fragmentadas organizacionalmente e dispersas espacialmente, têm se constituído em uma nova estrutura que impulsiona cada vez mais a economia mundial. Partindo dos conceitos de densidade, distância e divisão, considerados pelo Relatório de Desenvolvimento Mundial do Banco Mundial de 2009 como fatores determinantes para se forjar o desenvolvimento regional, este artigo objetiva analisar a maneira pela qual o setor de petróleo e gás no Brasil tem se conectado às RPGs, as condições que beneficiam e dificultam essas conexões, e as implicações disso para o desenvolvimento regional.

Palavras-chave: Densidade, Distância e divisão; Redes de produção globais; Setor de petróleo e gás; Brasil.

\section{Abstract}

\section{Density, distance, division and global production networks: the case of Brazil's oil and gas sector}

In addition to fostering increased trade between countries, globalization has significantly changed economic processes by enabling companies to divide production and marketing chains into various segments, which have

* Artigo recebido em 11 de novembro de 2017 e aprovado em 24 de setembro de 2018. Este artigo é resultado do projeto de pesquisa "Gateway cities and their hinterland: global cities from the global south as nodes in global commodity chains", que foi financiado pela Fapesp (Fundação de Amparo à Pesquisa do Estado de São Paulo) e pela DFG (Sociedade Alemã de Amparo à Pesquisa).

** Pesquisador da Universidade Livre de Berlim, Berlim, Alemanha. E-mail: soeren.scholvin@fu-berlin.de.

${ }^{* * *}$ Professor do Instituto de Economia da Universidade Estadual de Campinas (IE/Unicamp), Campinas, SP, Brasil. E-mail: mserra@unicamp.br.

${ }^{* * * *}$ Professora do Instituto Federal de Educação, Ciência e Tecnologia de São Paulo (IFSP), Campinas, SP, Brasil. E-mail: marisfrancoso@gmail.com.

****** Pesquisadora do Núcleo de Economia Industrial e da Tecnologia do Instituto de Economia da Universidade Estadual de Campinas (NEIT/IE/Unicamp), Campinas, SP, Brasil.

${ }^{* * * * * *}$ Professora do Departamento de Gestão de Políticas Públicas da Universidade de Brasília (UnB), Brasília, DF, Brasil. E-mail: apvbastos@gmail.com.

******* Supervisora de Pesquisas da Fundação Getúlio Vargas (FGV), São Paulo, SP, Brasil. E-mail: patricia.mello@fgv.brt.

******** Pesquisador do MIT Sustainable Urbanization Lab, Cambridge, MA, USA. E-mail: abcosta@ mit.edu.

********** Pesquisador do Centro de Estudos em Política e Economia do Setor Público da Fundação Getúlio Vargas (Cepesp/FGV), São Paulo, SP, Brasil. 
spread throughout the world. Therefore, organizationally fragmented and spatially dispersed global production networks (GPNs) have become a new structure that is increasingly driving the world economy. Based on the concepts of density, distance and division, which are deemed by the World Bank's World Development Report 2009 as determining factors of forging regional development, this article aims to analyze the way in which Brazil's oil and gas sector has connected to GPNs, the conditions that benefit as well as hinder these connections and the implications of this for regional development.

Keywords: Density; Distance and division; Global production networks; Oil and gas sector; Brazil. JEL O18, R120.

\section{Introdução}

A globalização, além de promover o aumento do comércio entre países, tem sido determinante na mudança dos processos econômicos na medida em que possibilita que as empresas compartilhem as cadeias de produção e comercialização em diversos segmentos ao redor do mundo. As cadeias de valor globais e as redes de produção globais (doravante denominada RPGs) "se tornaram a espinha dorsal e o sistema nervoso central da economia mundial" (Cattaneo; Gereffi; Staritz, 2010, p. 7). Segundo Coe e Yeung (2015), as RPGs, fragmentadas organizacionalmente e dispersas espacialmente, constituem uma nova forma de estrutura econômica que impulsiona cada vez mais a complexa economia global, mas nem sempre de forma equânime em termos de desenvolvimento.

A fragmentação espacial dos processos econômicos significa que o desenvolvimento regional depende de como as regiões se conectam às RPGs. A abordagem das RPGs, um dos conceitos mais utilizados na Geografia Econômica, requer a análise da interação das dinâmicas global e regional: "o desenvolvimento regional pode [...] ser conceituado como um resultado dinâmico da complexa interação entre redes específicas da região e redes de produção globais" (Coe; Yeung, 2015, p. 18). Em outras palavras, a configuração econômica de uma região, ou seja, os recursos humanos e não humanos disponíveis em locais específicos, deve corresponder às necessidades das empresas transnacionais para que o investimento estrangeiro possa ser desencadeado.

Alguns aspectos do setor de petróleo e gás no Brasil são analisados neste artigo, que centra a atenção em três relevantes questões: a maneira pela qual o setor tem se conectado às RPGs, as condições que beneficiam e dificultam essas conexões, e o significado disso para o desenvolvimento regional. Em 2006, após a descoberta de novos depósitos offshore, o setor teve um forte impulso e se tornou mais complexo. Uma vez que a exploração de petróleo em águas ultra-profundas requer pesados investimentos em serviços e tecnologias, a Petrobras, ainda que detentora da tecnologia, tem explorado, em parceria com empresas estrangeiras, como a Chevron, a Halliburton e a Shell, o petróleo em águas profundas. Cabe aqui salientar que já existe, no Estado de São Paulo, uma significativa participação de empresas locais no setor downstream ${ }^{1}$. E quanto às atividades upstream, importa destacar que, embora estimuladas

(1) A indústria de petróleo e gás é usualmente dividida em três setores: downstream, midstream e upstream. Este último setor inclui a busca por campos de petróleo e gás, e a perfuração e operação de poços. O setor midstream abrange o transporte, a armazenagem e a comercialização por atacado de produtos brutos ou purificados/refinados. Já o setor downstream compreende tanto o refinamento de petróleo bruto e a purificação do gás natural in natura, quanto a comercialização e distribuição de produtos derivados do petróleo e gás. 
em Santos, elas ainda se concentram no Rio de Janeiro, que é o tradicional polo deste setor no país e onde estão localizadas a sede da Petrobras e os escritórios nacionais de seus parceiros estrangeiros. Recentemente, a Petrobras foi afetada tanto pelos escândalos de corrupção, quanto pelo declínio mundial dos preços do petróleo, o que tem gerado uma paralisação em todo o setor.

A coleta de dados empreendida neste artigo se baseia em fontes primárias e secundárias (especialmente os bancos de dados "A Barrel Full" e RAIS), bem como em entrevistas realizadas nas cidades de São Paulo, Santos e Rio de Janeiro entre 2014 e 2016 . A análise das informações empíricas foi ancorada no arcabouço teórico fornecido pelo Relatório de Desenvolvimento Mundial de 2009, que estabelece três fatores causais que moldam o desenvolvimento regional: densidade, distância e divisão - os três Ds. Acredita-se que a mera participação nas RPGs, que podem ser explicadas pelos três Ds, não é uma condição suficiente para o desenvolvimento regional. No entanto, a contextualização do setor brasileiro de petróleo e gás foi refinada pelo uso da abordagem da RPG, em que se verifica tanto a maneira pela qual o valor é criado, aprimorado e capturado, quanto a influência de diferentes formas de poder e integração no setor.

Este artigo está estruturado em quatro seções, além desta introdução. A apresentação da estrutura analítica - os três Ds e a abordagem das RPGs - é o foco central da segunda seção. Na seção subsequente, o desenvolvimento recente do setor de petróleo e gás no Brasil é analisado levando-se em consideração os três Ds e, ao mesmo tempo, sublinhando-se o importante papel desempenhado pelos parques tecnológicos de Santos e do Rio de Janeiro. Já a quarta seção explora o casamento das informações empíricas apresentadas na seção anterior com a abordagem das RPGs. Na quinta e última seção, algumas considerações finais são tecidas.

\section{Estrutura analítica}

Conforme explicado anteriormente, este artigo parte dos conceitos apresentados no Relatório de Desenvolvimento Mundial, de 2009, do Banco Mundial, que está centrado em três fatores considerados decisivos para o desenvolvimento econômico: densidade, distância e divisão. Por densidade se entende a aglomeração de empresas e de consumidores, que é o motor fundamental do desenvolvimento econômico: "avançar para a densidade econômica é um caminho para sair da pobreza, tanto para os que viajam nela como para os que ficam para trás" (World Bank, 2009: 49). Para explicar como os impulsos econômicos se espalham dessas aglomerações para a periferia, o Banco Mundial acrescenta distância e divisão como fatores determinantes: a distância está relacionada ao custo e ao tempo para se transportar bens, informações e pessoas, ao passo que a divisão contempla as barreiras tarifárias e não-tarifárias como, por exemplo, as diferentes linguagens de negócios.

A análise do setor de petróleo e gás na África Subsaariana sugere que a periferia e a semi-periferia da economia global dependem de "cidades de entrada" para se conectarem às RPGs (Scholvin, 2017). De fato, estas cidades, ao oferecerem um certo grau de densidade 
combinado com um ambiente institucional sofisticado e boa infraestrutura de transporte, acabam por conectar as regiões periféricas globalmente. A densidade é concebida neste artigo, em contraste com a concepção defendida no Relatório do Banco Mundial, como a concentração de empresas que contribuem para uma RPG específica. Considerando que a densidade é um fator que permite que lugares se conectem às RPGs, a distância e a divisão são os principais obstáculos a tais processos porque limitam os fluxos que atingem um determinado lugar. Por exemplo, Scholvin e Malamud (2014) mostram que a extensão territorial da América do Sul, suas inúmeras barreiras físicas e a virtual ausência de infraestrutura de transporte no interior do continente dificultam a interação econômica entre o Brasil e a Guiana, Suriname, Venezuela e os países andinos. Um exemplo ilustrativo, mencionado por Scholvin (2017), é o das barreiras linguísticas - isto é, a divisão - enfrentadas pelas empresas sediadas na Cidade do Cabo para realizarem negócios nos diversos países da África Subsaariana que têm abundantes recursos de petróleo e gás.

Um aspecto importante de ser salientado aqui é o fato de o Relatório de Desenvolvimento Mundial, de 2009, condensar os principais debates nas áreas de Economia e da Geografia Econômica, ilustrando os principais fatores causais, tradicionalmente considerados relevantes, e os traduzir em recomendações políticas. Os geógrafos econômicos criticaram o Relatório e a teoria de Krugman (1991a; 1991b; 1992), que serviu de referência para o próprio Relatório, tanto pela excessiva simplificação, quanto pelo desconhecimento das especificidades locais e temporais (Martin; Sunley, 1996; Rodríguez-Pose, 2010). É em virtude da relevância de alguns dos argumentos dessa crítica que os três Ds são utilizados como pontos de partida da análise empreendida nesse artigo, no qual se examina como eles se relacionam em contextos locais específicos e com as particularidades das RPGs do setor de petróleo e gás.

Cabe aqui sublinhar que a conexão com as RPGs não é uma condição suficiente para um desenvolvimento duradouro, é apenas um primeiro passo. Uma vasta literatura produzida nos anos 1970 e 1980 mostrou que as regiões periféricas tinham se tornado locais para os segmentos das cadeias de valor pouco qualificadas e mais ordinárias em capital intensivo. As atividades de elevado nível de comando e concepção permaneceram nas regiões economicamente mais desenvolvidas do mundo. O investimento em sucursais pouco ofereceu aos países em desenvolvimento em termos de oportunidades de encadeamento, de reinvestimento de lucros, de constituição de competências e de transferência de tecnologia (Firn, 1975; Dicken, 1976; Watts, 1981; Amin; Tomaney, 1995). Porém, no início da década de 1990 surgiu um padrão bastante diferente, em que as denominadas fábricas de desempenho foram cada vez mais marcadas pela autonomia, complexa funcionalidade, mercados especializados, intensificação nas tecnologias de produtos e processos, e mão-de-obra qualificada (Pike, 1998; Phelps et al., 2003). No tocante às regiões hospedeiras das fábricas de desempenho, as oportunidades de desenvolvimento econômico surgiram em função da integração dessas fábricas por meio de fortes encadeamentos localizados para frente e para trás entre fornecedores (Turok, 1993). Além disso, os requisitos de força de trabalho das fábricas de desempenho tornaram-se um motor dos processos de qualificação da mão-de- obra local (Phelps; Fuller, 2000; Raines, 2003). 
A abordagem das RPGs não é tão diferente da pesquisa sobre as sucursais e fábricas de desempenho. Ela lança mais luz sobre fatores específicos relacionados ao investimento estrangeiro, especialmente os arranjos institucionais em um sentido bastante amplo. Na realidade, esta abordagem não apenas trata de como os fluxos moldam regiões, mas também de como as regiões moldam fluxos (Coe et al., 2004; Henderson et al., 2002). Coe, Dicken e Hess (2008, p. 272) argumentam que ela fornece uma estrutura que visa "incorporar todos os tipos de relações de redes" e, ao mesmo tempo, "englobar todos os conjuntos relevantes de atores e relacionamentos" associados a um determinado processo econômico.

Henderson et al. (2002) propõem três categorias analíticas para examinar sistematicamente como um determinado lugar se conecta a uma RPG específica: (a) o valor, (b) o poder, e (c) o nível de envolvimento (ver Figura 1). Em relação à primeira categoria, o valor refere-se tanto à conversão da força de trabalho em mão-de-obra efetiva, quanto ao retorno econômico ou à renda gerada pela produção de bens e serviços. Este último implica que o valor pode ser criado através do controle de recursos humanos e naturais (renda de recursos), das tecnologias (renda tecnológica), do acesso desigual ao sistema financeiro (renda financeiro) e à infraestrutura (renda de infraestrutura), do desenvolvimento de capacidades organizacionais (renda organizacional), do aproveitamento das relações interfirmas (renda relacional), e da proeminência de marcas (renda de marcas). Se as empresas tiverem capacidade para influenciar as políticas em benefício próprio, como, por exemplo, as políticas comerciais, haverá uma renda política (Kaplinsky, 1998; 2005). Diferentes empresas são capazes de criar e gerar diferentes tipos de rendas para distintas dimensões.

Figura 1

Valor, poder e envolvimento

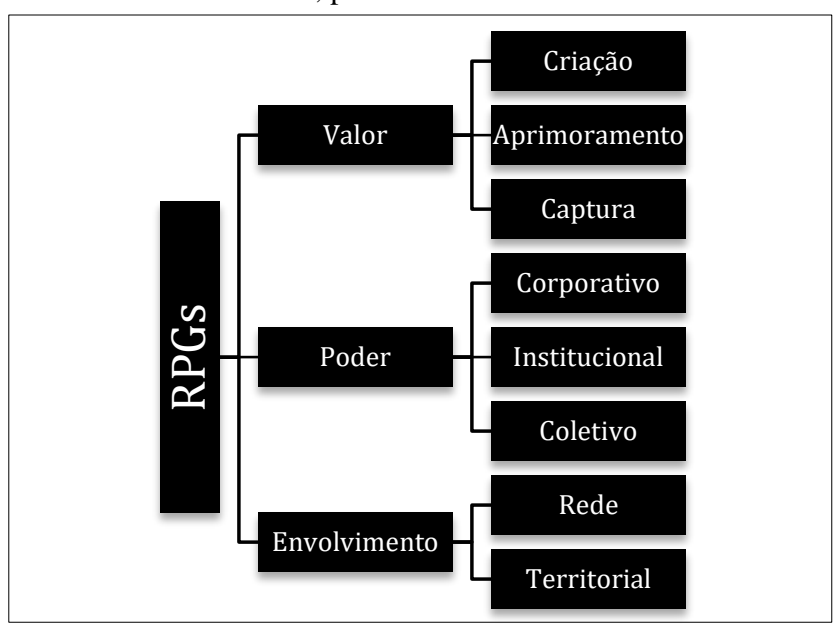

Fonte: Elaboração própria com base em Henderson et al. (2002).

Além da criação de valor, é importante saber como o valor é aperfeiçoado por empresas específicas em determinados locais, ou seja, como elas melhoram a criação de valor de modo 
a tornar os bens e serviços existentes superiores e, portanto, mais valiosos. A demanda por mão-de-obra qualificada aumenta nos locais em que há valorização, o que faz com que as firmas locais se tornem capazes de criar tipos mais sofisticados de rendas próprias (Henderson et al., 2002). Entretanto, há uma diferença significativa entre o valor a ser criado e aprimorado em uma região que tenha se conectado a uma RPG e o valor a ser capturado localmente. A captura de valor está intrinsecamente relacionada a temas de políticas públicas que afetam, por exemplo, as leis da estrutura de propriedade e de repatriamento dos lucros (Henderson et al., 2002). É exatamente nesse sentido que Coe e Yeung (2015, p. 172) argumentam que "para fins de desenvolvimento econômico, o valor deve ser mantido dentro das firmas, ou de partes delas, sediadas no território em questão".

Figura 2

Criação, aprimoramento e captura de valor

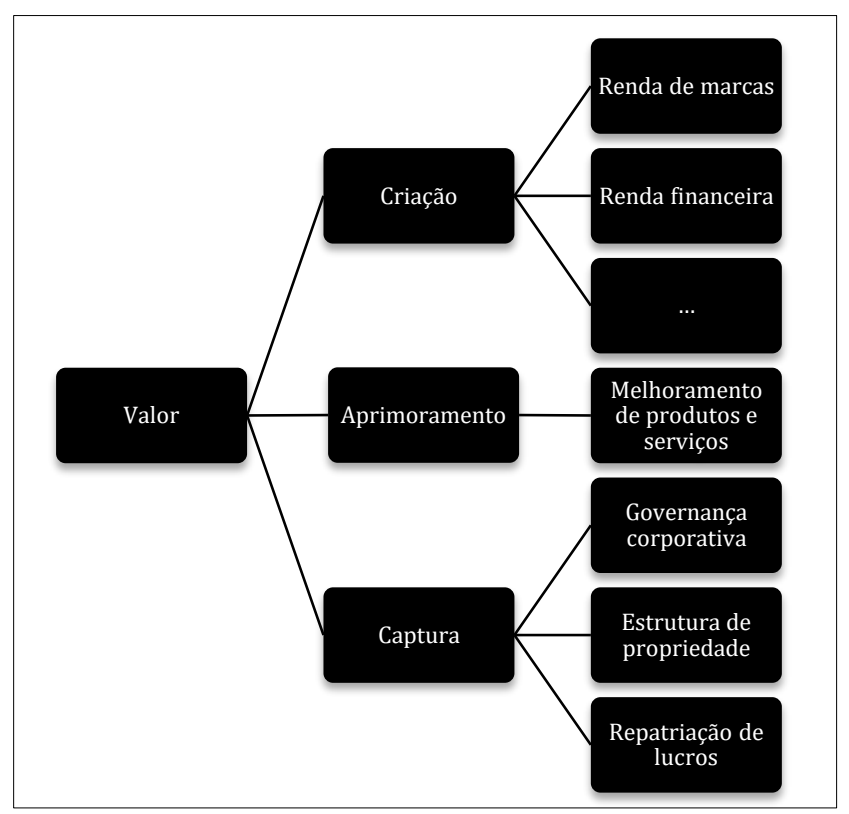

Fonte: Elaboração própria com base em Coe et al. (2004).

Quanto ao poder, a segunda categoria analítica (ver Figura 1), cabe aqui sublinhar que as RPGs - e a captura de valor agregado, em particular - são influenciadas por três de suas formas: (a) o poder corporativo, que está associado ao controle efetuado pelas empresas líderes sobre suas parceiras; (b) o poder institucional, que está intrinsecamente relacionado ao exercício das autoridades subnacionais, nacionais e internacionais no tocante às firmas, em que a determinação de um conteúdo local ou a garantia do investimento estrangeiro são exemplos ilustrativos; e (c) o poder coletivo, que é realizado por associações empresariais, sindicatos e organizações similares. 
Além disso, Coe e Yeung (2015) fazem uma distinção entre os parceiros estratégicos das empresas líderes, os fornecedores especializados e os fornecedores genéricos na medida em que essa diversidade de empresas caracteriza uma região que participa de uma RPG sozinha ou em diferentes combinações. Os parceiros estratégicos são os que fornecem soluções completas ou, no mínimo, parciais para as empresas líderes por meio de projetos cooperativos ou do desenvolvimento de manufaturas e serviços, ao passo que os fornecedores especializados não estão envolvidos nessas atividades. De fato, se somente fornecem bens e serviços intermediários às empresas líderes, logo exercem menos poder e, assim, capturam menor valor. Os fornecedores especializados englobam as empresas específicas ou multi-industriais. A contribuição das empresas genéricas difere no que tange à sofisticação. Estas empresas fornecem produtos e serviços altamente padronizados e de menor valor à empresa líder, o que faz com que não só exerçam menos poder na cadeia como também capturem menor valor.

Em relação à terceira categoria analítica (ver Figura 1), dois tipos de envolvimento são responsáveis por moldar as RPGs: o envolvimento em rede e o envolvimento territorial. O primeiro apreende as relações econômicas, institucionais e sociais das empresas integradas nas RPGs, sendo a estabilidade de suas relações com outras empresas na rede ou a relevância da rede para seus negócios, exemplos ilustrativos. Já o segundo diz respeito à fixação das RPGs em locais específicos, fato este que pode ser causado, por exemplo, pela sua dependência de mercados ou de recursos. Nesse sentido, as regiões devem também reforçar o envolvimento territorial das empresas líderes, intensificando cada vez mais os vínculos existentes.

Desse constructo deriva o argumento de que a "ligação estratégica" decide se, e como, as regiões se conectam às RPGs. De acordo com Yeung (2009, p. 213), a "ligação estratégica refere-se aos processos dinâmicos através dos quais os atores das cidades e/ou regiões coordenam [...] os interesses estratégicos entre os atores locais e as suas contrapartes na economia global". A ligação estratégica, no entender de Coe e Yeung (2015, p. 20), "necessita de intervenção intencional e ativa de instituições regionais e de poderosos atores da rede de produção global". Deste modo, as autoridades públicas asseguram que os ativos regionais sejam moldados e forjados para atender às necessidades dos investidores estrangeiros através, por exemplo, da oferta de infraestrutura mais avançada ou de programas de educação e formação que aumentem as capacidades das redes de fornecedores locais.

Há três tipos de ligação estratégica: endógena, funcional e estrutural (Coe; Yeung, 2015). A ligação endógena está relacionada aos processos de dentro para fora: as empresas locais chegam de uma região para participar nas RPGs (ou então para criar novas). Essas empresas são geralmente bastante autônomas e captam uma parcela considerável do valor gerado nas respectivas RPGs. A ligação funcional diz respeito às empresas de uma região que atendem às necessidades de uma RPG. Os graus de autonomia e de captura de valor das empresas envolvidas neste tipo de ligação são menores do que na ligação endógena, embora a ligação funcional não seja necessariamente um processo de fora para dentro. Já a ligação estrutural capta os processos de fora para dentro: as empresas externas vinculam a região à RPG por causa dos ativos da região. Este acoplamento tende a ser caracterizado por propiciar 
reduzida autonomia e captura de valor para as empresas regionais. No que tange à tipologia das empresas mencionadas anteriormente, pode-se argumentar que parceiros estratégicos de empresas transnacionais, e as próprias empresas transnacionais, realizam ligações endógenas, enquanto a ligação funcional se aplica aos fornecedores especializados e a ligação estrutural aos genéricos.

Figura 3

Ligação estratégica

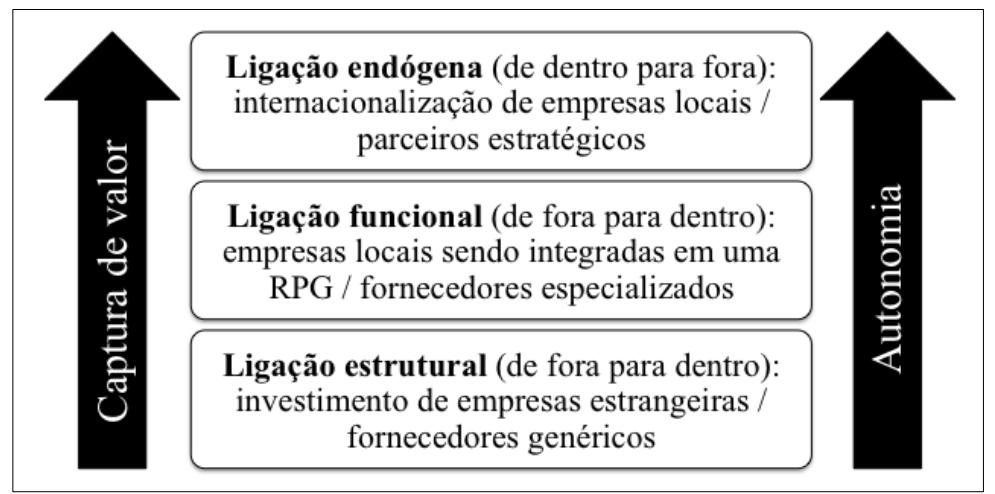

Fonte: Elaboração própria com base em Coe e Yeung (2015).

É interessante notar que importantes pesquisas sobre as RPGs parecem ignorar aquelas regiões que não estão integradas - ou o estão apenas em um grau limitado - aos processos econômicos globais, ou seja, tendem a se concentrar nos casos de sucesso em que o desenvolvimento econômico das regiões se deve à profunda integração destas às RPGs. Dois exemplos ilustrativos são o artigo seminal de Coe et al. (2004), que explora o caso da empresa alemã BMW, fabricante de automóveis e motocicletas e dos numerosos locais que participam de sua RPG, e o livro Global Production Networks, que resume o estado da arte na pesquisa sobre as RPGs (Coe; Yeung, 2015). Não deixa de ser significativo o fato de essa tendência também se manifestar nas pesquisas sobre os processos de separação. Nesse sentido, Horner (2014), baseado na indústria farmacêutica da Índia, mostrou como um processo deliberado de separação, seguido de uma religação, possibilitava o desenvolvimento econômico.

Determinadas análises sobre o Sul Global enfatizaram que as histórias de sucesso parcial das regiões estão diretamente relacionadas ao seu grau de integração às RPGs. Um exemplo ilustrativo dessa literatura é o artigo de Murphy e Schindler (2011), que examina a criação, o aprimoramento e a captura de valor por parte de fornecedores bolivianos de empresas transnacionais da indústria madeireira com o propósito de descobrir como a Bolívia poderia obter maiores benefícios da globalização econômica. O ponto crucial, no entanto, é o fato de ambos os autores não terem percebido que os reduzidos efeitos benéficos advindos da globalização estavam diretamente relacionados à falta ou à insuficiência de envolvimento das empresas bolivianas, formais e informais, nas RPGs. O mesmo se aplica a muitas empresas 
brasileiras de engenharia do setor de petróleo e gás, o que será examinado na seção subsequente.

No entanto, cabe aqui recapitular que o argumento central desta seção é que a abordagem das RPGs é insuficiente para explicar tanto o insucesso na ligação com as RPGs, quanto a acentuada limitação desses processos de ligação. Nesse sentido, a explicação se torna mais robusta com a análise dos três Ds, que complementam a abordagem da RPG e, consequentemente, preenchem uma importante lacuna conceitual de pesquisa.

Na seção subsequente, o setor de petróleo e gás brasileiro é contextualizado para melhor se compreender o envolvimento destas empresas com o território.

\section{O setor de petróleo e gás no Brasil}

No Brasil, os recursos petrolíferos comprovados estão estimados em 15 bilhões de barris, o que o coloca em segundo lugar na América do Sul, logo atrás da Venezuela. Quase 95\% desses recursos estão localizados no mar, sendo que $80 \%$ deles encontram-se na costa do Estado do Rio de Janeiro. Além disso, o Brasil também possui a segunda maior reserva de gás natural da América do Sul, a qual está primordialmente situada na Bacia de Campos. Apesar de a exploração e a extração offshore do petróleo não se constituir em novidade, foi somente em 2006 que grandes quantidades foram encontradas. De fato, são depósitos ultra-profundos, localizados abaixo das camadas de sal, o que dificulta a sua exploração ${ }^{2}$. Ainda assim, o Brasil, em 2009, tornou-se um exportador líquido de petróleo bruto. Em 2011, o consumo doméstico voltou a superar a produção doméstica, sendo que ambos atingiram o mesmo patamar em 2015. No ano anterior, o Brasil extraiu 179,8 milhões de barris de petróleo do pré-sal e 6,3 bilhões de metros cúbicos de gás do pré-sal (Energy Information Administration, 2015).

Um aspecto importante de ser sublinhado é o fato de o Brasil, ao longo de décadas, continuar sendo um importador líquido de derivados de petróleo refinado. As refinarias brasileiras foram projetadas para processar petróleo bruto leve e não têm capacidade técnica para processar os recursos recém-encontrados, de densidade pesada. Pode-se perceber o porquê da importação de petróleo leve para suprir a demanda interna e a exportação de petróleo pesado, que não possui demanda interna, somente do exterior.

Torna-se importante destacar que o crescimento da economia brasileira antes da crise que começou no ano 2014 teve uma correlação elevada com o setor de petróleo e gás, que responde por cerca de $60 \%$ do suprimento de energia do país. Devido a um maior acesso a bens elétricos de uso doméstico, este tipo de consumo de energia doméstica praticamente dobrou de 2004 até 2014 (Energy Information Administration, 2015). As principais descobertas de petróleo e gás do Brasil ocorreram nos anos 2000, durante o super-ciclo das commodities (Pinar

(2) Bicalho et al. (2009) identificam cinco áreas onde é necessário desenvolver soluções tecnológicas: ancoragem e manejo de dispositivos flutuantes, logística associada ao gás natural, caracterização de reservatórios, risers (tubos) em áreas submarinas e perfuração de poços. 
Erdem; Ünalmis, 2016), que se beneficiou, em grande medida, da crescente demanda dos mercados emergentes - principalmente, China - e Brasil. Outro importante fator a ser considerado são as preocupações com a disponibilidade de fornecimento a longo prazo. Internacionalmente, o preço do petróleo atingiu, em 2008, um pico de US\$147 o barril, mas, a partir daí, o preço começou a cair acentuadamente devido à crise financeira global, voltando a aumentar mais tarde em função não só da crise da pós-Primavera Árabe, no Oriente Médio, como, também, das sanções ocidentais impostas ao Irã por causa do seu programa nuclear.

A elevação dos preços das commodities no mercado mundial contribuiu para o bom desempenho tanto da economia brasileira quanto da latino-americana no período anterior à crise econômica, sendo que a razão desta boa performance, em que o crescimento econômico anual médio de aproximadamente 5\% da região no período de 2003 a 2008 foi superior ao dos países da OCDE, está essencialmente baseada numa adequada gestão macroeconômica (OCDE/Cepal, 2011). Os países latino-americanos reduziram a dívida pública, geraram superávit fiscal e fortaleceram a estabilidade macroeconômica, aspectos fundamentais para que os impactos da crise financeira global fossem enfrentados e mitigados. Especificamente em relação ao Brasil, o boom das commodities propiciou ao governo federal os recursos necessários para a implementação de políticas públicas direcionadas ao combate à pobreza e à desigualdade de renda. No período de 2003 a 2013, a taxa média de crescimento do PIB foi cerca de 3,8\% (Ipea, 2017), mesmo após a crise mundial de 2008. O índice de Gini, que era 0,63 em 1989, o segundo mais elevado do mundo, na época, caiu para 0,52, em 2013 (Ipea, 2017), ao passo que o crescimento da renda dos $40 \%$ mais pobres, entre 2004 e 2014, foi de $6,8 \%$ ao ano, um percentual bem superior à média de 4,5\% entre todos os brasileiros (World Bank, 2016). Dentro do contexto das políticas sociais, cabe aqui mencionar o Programa Bolsa Família, que teve um significativo impacto na redução da pobreza, principalmente na extrema pobreza. De acordo com Cotta e Paiva (2010), das 12,4 milhões de famílias beneficiárias, em 2009, aproximadamente 4,3 milhões superaram a linha da extrema pobreza, sendo 48,7\% o aumento da renda familiar mensal, chegando este benefício a atingir $60 \%$ nas regiões Norte e Nordeste.

Com a descoberta do pré-sal, os recursos do petróleo e do gás passaram a fazer parte dos planos do governo federal como um elemento-chave da sua agenda de desenvolvimento para o país. Este desenvolvimentismo, caracterizado essencialmente pelo forte papel do Estado e das empresas estatais na economia, constituiu uma alternativa ao liberalismo baseado no Consenso de Washington, que moldou, antes de 2003, a política de petróleo e gás do Brasil, levando à liberalização do setor e, ao mesmo tempo, à privatização parcial da Petrobras ${ }^{3}$.

Alguns autores (Sicsú; De Paula; Michel, 2007; Erber, 2010; Bresser-Pereira, 2011) apresentam outra perspectiva ao salientar que um Estado desenvolvimentista deveria facilitar

(3) Garcia Ribeiro e Tahan Novaes (2016), fornecem uma análise detalhada das mudanças organizacionais detalhadas que a Petrobras tem passado desde a sua criação em 1953. 
o desenvolvimento econômico através de políticas industriais focadas no conteúdo local, inovação e investimento em setores estratégicos, incluindo o de petróleo e gás. Eles ressaltam que a diminuição da desigualdade e investimento em capital humano são cruciais para o desenvolvimento. Acrescentam que a aposta no desenvolvimento setorial, a partir de uma política de conteúdo local, permitiria o desenvolvimento do mercado interno e de capacidades de produção, que têm sido tradicionalmente a essência de políticas de desenvolvimento em outros países. O Estado deveria, também, elaborar um plano de longo prazo para o desenvolvimento nacional e, portanto, influenciar processos que políticos de viés mais liberal deixariam a cargo das forças de mercado (Schutte, 2013). Autores favoráveis a um modelo mais desenvolvimentista sublinham que a própria descoberta do pré-sal não teria sido possível sem o investimento público de longo prazo em tecnologias de risco, cujo início se deu em 1955 e foi intensificada a partir da década de 1980 (Serrani, 2013).

Um fator crucial do desenvolvimentismo no Brasil foi a criação, em 2009, da empresa estatal Pré-Sal Petróleo SA, que é responsável por administrar os recursos do pré-sal, incluindo a concessão de licenças (Lei n. 12.304/10) ${ }^{4}$. Nesse marco regulatório, foi criado um sistema de contratos compartilhados em que o Estado obtém royalties e impostos do setor de petróleo e gás. Ficou definido que parte desses recursos seriam canalizados para fundos especificamente relacionados às áreas de educação e saúde (Lei n. 12.558/13). O petróleo produzido a partir da descoberta do pré-sal também seria dividido entre as petrolíferas e o Estado. Caso a exploração falhasse, as empreiteiras arcariam com as perdas financeiras (Lei n. 12.351/10).

Além do Estado brasileiro adquirir petróleo das reservas do pré-sal, uma lei aprovada em 2010 especificava que a Petrobras seria a única operadora de cada projeto do pré-sal, mantendo pelo menos $30 \%$ das participações em acordos de compartilhamento de produção com parceiros estrangeiros. A Petrobras poderia (e ainda pode), também, ter $100 \%$ da propriedade dos blocos do pré-sal sem passar por um processo de licitação competitiva (Lei ${ }^{\circ}$ 12.351/10). Em 2016, esta legislação foi adaptada pelo governo Temer, que deu à Petrobras o direito de preferência: se a empresa se recusar a participar de novos projetos do pré-sal, as licenças de acordo podem ser completamente concedidas aos investidores estrangeiros (Lei n. 13.365/16).

O Brasil também teve rígidas exigências acerca do conteúdo local. Entre elas, ficou definido que a Petrobras (e suas subsidiárias) exigiria, para cada bloco, que um percentual específico dos seus equipamentos, serviços e força de trabalho fosse nacional. Para garantir o cumprimento destas medidas, um sistema para certificar e controlar o conteúdo local foi estabelecido pela Agência Nacional de Petróleo (ANP). Nas rodadas de oferta dos novos blocos, os investidores potenciais são obrigados a contratar elevados percentuais de conteúdo local, de acordo com a resolução n. 19, de 2013, da ANP -, que define a certificação do

(4) A este respeito, consultar www44.planalto.gov.br/legislação. 
conteúdo local (agora substituída pela resolução n. 26, de 2016) 5 . Embora a Petrobras domine parte da tecnologia de exploração de águas profundas, muitos equipamentos altamente sofisticados exigidos para a exploração dos recursos do pré-sal, frequentemente não estão disponíveis no Brasil, sendo esta parte da explicação dada pelos agentes envolvidos para o fato da legislação de conteúdo local ter gerado gargalos e desacelerado a exploração dos recursos.

Outras razões podem ser apontadas, tais como a investigação da operação "lava-jato" e a crise internacional do petróleo, em 2014, que fez despencar os preços e diminuiu a capacidade de manter o nível de investimentos previstos, o que acabou por afetar o papel de liderança da Petrobras. Deste modo, a exploração e a extração de petróleo ficaram, pelo menos até 2016, limitadas à capacidade da Petrobras de investir. No entanto, não é negligenciável que a legislação de conteúdo local proporcionou oportunidades para empresas brasileiras e atraiu empresas estrangeiras para que investissem no Brasil. A título de ilustração, a legislação de conteúdo local permitiu o ressurgimento, na segunda metade da década de 2000, da agonizante indústria naval no Rio de Janeiro (Frassa et al., 2011), com todos os multiplicadores regionais que daí advém.

O diretor de uma empresa estrangeira de prestação de serviços upstream ressaltou não haver, tanto em termos de mão de obra qualificada quanto de fornecedores experientes, grandes desafios no Brasil, uma vez que o país dispunha de todos os serviços de engenharia. A partir de 2006, muitas empresas, inclusive a do próprio diretor, construíram estaleiros com o propósito de montar equipamentos para as atividades offshore. Assim, cumpria-se a legislação de conteúdo local e, ao mesmo tempo, forjava-se uma base de fornecedores locais. O problema, no entanto, residia no fato de esse mercado para equipamentos sofisticados ser oligopolizado e global. Essas características induziram as empresas, em virtude das economias de escala, a optar por montar boa parte dos equipamentos, após seguir as obrigações da legislação de conteúdo local, no exterior, especialmente na China ${ }^{6}$.

Outrossim, as entrevistas institucionais, que foram realizadas com o intuito de compreender a percepção dos atores a respeito da recente dinâmica do setor do petróleo e gás no Brasil, corroboraram os problemas da legislação de conteúdo local, fundamentalmente na sua concepção. Um representante da ANP sublinhou que a Petrobras detinha informações sobre as limitações de competitividade na capacidade instalada na indústria brasileira e não as publicou, o que gerou sérias dificuldades no estabelecimento dos contratos. Ademais, algumas empresas sobrestimaram sua capacidade de produção e muitas vezes, para cumprir prazos e preços, importaram produtos intermediários ofertados de forma mais competitiva no mercado internacional, rompendo, de um certo modo, os contratos de cota de conteúdo local ${ }^{7}$. Já os coordenadores da Confederação Nacional da Indústria acrescentaram ainda que faltava

(5) A este respeito, consultar www.anp.gov.br/wwwanp/rodada-legislacao.

(6) Entrevista, realizada em Guarujá em 19 de abril de 2017, com um diretor local de uma empresa internacional de prestação de serviços upstream.

(7) Entrevista, realizada em Brasília em 27 de abril de 2017, com um representante da ANP. 
transparência nos apoios concedidos ${ }^{8}$, ao passo que os representantes do Ministério de Minas e Energia e da própria ANP ressaltaram que as empresas clamavam somente por reserva de mercado, sendo esta uma das razões para que muitos dos incentivos não se traduzissem em inovações e aumento de competitividade. Na realidade, a crise revelou que o comportamento de evitar riscos e promover investimentos em inovação e produtividade desacelerou a competitividade das empresas contratantes, pois prazos, custos e qualidade nem sempre eram cumpridos ${ }^{9}$.

No entanto, a percepção de representantes do Ministério de Relações Exteriores foi a de que os empresários apresentavam comportamentos oportunistas e negociavam as multas referentes ao não cumprimento das cláusulas dos contratos diretamente com os reguladores ${ }^{10}$. É oportuno mencionar que o representante da ANP ratificou esse comportamento, que era verificado nas empresas, tanto nacionais quanto estrangeiras, que participaram dos leilões. Para ilustrar esse comportamento oportunista, ele forneceu o exemplo da perda de um campo de Libra da Petrobrás para a Devon, que havia oferecido um bônus mais baixo e um percentual de conteúdo local mais elevado, acima da sua capacidade instalada, o que inflacionou a oferta final e postergou os pagamentos a serem efetuados, isto porque a aposta era de que a capacidade seria instalada ou então de que as possíveis multas por não cumprimento da legislação seriam negociadas no futuro ${ }^{11}$.

Em que pese às diferenças existentes nos depoimentos, há um consenso entre os atores institucionais em relação a três pontos cruciais: (a) os programas e incentivos para o desenvolvimento de fornecedores locais nos diferentes segmentos da cadeia produtiva - tais como o Programa de Mobilização da Indústria Nacional de Petróleo e Gás Natural que, além dos incentivos, contribuiu para a formalização da política de conteúdo nacional ao definir, de forma explícita, a metodologia de cálculo do conteúdo local, que foi consolidada no Índice de Conteúdo Local - tiveram formatos incompletos e, portanto, necessitavam de ajustes, que não ocorreram devido à mudança de regime, à crise de preços internacionais e à operação lava-jato; (b) a indústria não teve tempo de estabelecer a curva de aprendizagem e se desenvolver, pois uma década não era suficiente para que as empresas se tornassem competitivas internacionalmente; e (c) a descoberta do pré-sal produziu no governo federal um excessivo otimismo e, ao mesmo tempo, uma previsão de investimento que não chegou a se concretizar com o início das investigações da lava-jato, cuja consequência imediata foi a redução das expectativas de demanda das empresas subsidiárias, que deixaram de investir preventivamente.

Conforme os parágrafos acima indicam, a legislação de conteúdo local sofreu, ao longo de sua existência, várias alterações, que estão irremediavelmente atreladas a uma visão de

(8) Entrevista, realizada em Brasília em 4 de maio de 2017, com representantes da Confederação Nacional da Indústria.

(9) Entrevistas, realizadas em Brasília em 26 e 27 de abril de 2017 respectivamente, com representantes do Ministério de Minas e Energia e com um representante da ANP.

(10) Entrevista, realizada em Brasília em 4 e 5 de julho de 2017, com representantes do Ministério de Relações Exteriores.

(11) Entrevista, realizada em Brasília em 27 de abril de 2017, com um representante da ANP. 
desenvolvimento não só do setor de petróleo e gás, mas também do próprio país. Embora elaborada em 1999, a política de conteúdo local tinha um caráter eminentemente voluntário em função do receio do governo federal de que ela fosse interpretada como uma medida protecionista e, por conseguinte, desencorajasse as empresas estrangeiras. Não é por outra razão que, nas quatro primeiras rodadas de 1999 a 2002, o percentual exigido para produtos e serviços nacionais era nulo (ANP, 2015; Santos; Avellar, 2017).

Foi exatamente a partir de 2003, com o início do governo Lula, que a política passou a ter um caráter compulsório, sendo determinados os percentuais para as três modalidades: águas profundas - 30\% para exploração e desenvolvimento; águas rasas - 50\% para a exploração e $60 \%$ para o desenvolvimento; e terra (em que os projetos, em termos técnicos, exigem menos desafios) - 70\% para exploração e desenvolvimento (ANP, 2003). Com o objetivo de impulsionar ainda mais a participação da indústria nacional de bens e serviços, houve uma elevação dos percentuais na sétima rodada, realizada em 2005, que ficaram assim definidos: águas profundas - de 37 a 55\% para a exploração e de 55 a $65 \%$ para o desenvolvimento; águas rasas - de 51 a $60 \%$ para a exploração e de 63 a $70 \%$ para o desenvolvimento; e terra - de 70 a $80 \%$ para a exploração e de 77 a $85 \%$ para o desenvolvimento (ANP, 2005).

Cabe aqui sublinhar que esses percentuais permaneceram inalterados por doze anos. Foi justamente na décima quarta rodada, ocorrida em 2017, que os níveis de conteúdo local sofreram uma nova modificação, com os percentuais estabelecidos da seguinte forma: águas profundas e águas rasas - $18 \%$ para a exploração e de 25 a $40 \%$ para o desenvolvimento; e terra $-50 \%$ para a exploração e o desenvolvimento. Convém ressaltar que essa redução foi significativa na medida em que os atuais patamares de conteúdo local são inferiores aos que haviam sido estipulados em 2003. A alegação do governo federal para essa alteração foi a de adequar as regras à realidade do mercado e do próprio setor de petróleo e gás e, ao mesmo tempo, a de flexibilizar o acesso de empresas estrangeiras ao setor, o que geraria maior capacidade produtiva e tecnológica, um grande estímulo a novos investimentos e uma aceleração do desenvolvimento do setor (ANP, 2018).

A principal razão das recentes mudanças na legislação de conteúdo local é a necessidade do Brasil de atrair investimento estrangeiro no setor de petróleo e gás, que resulta da crise da Petrobras. A Petrobras está sob investigação no Brasil e nos Estados Unidos por corrupção e lavagem de dinheiro. Enquanto a investigação esteve em andamento, o auditor da Petrobras não certificou suas demonstrações financeiras, o que a impediu de acessar mercados internacionais de capitais, reforçando os efeitos negativos da queda dos preços do petróleo. Como consequência, a empresa teve que empreender um plano de desinvestimento considerável para levantar fundos. A Petrobras (2016b) agora estima que sua produção de 
petróleo e gás atingirá 3,41 milhões de barris de petróleo equivalente por dia em $2021^{12}$, o que significa uma queda de $30 \%$ em relação ao seu planejamento anterior.

A crise da Petrobras - e a instabilidade econômica e política do Brasil em geral certamente tem afetado a forma como o país se conecta às RPGs de petróleo e gás. Entretanto, o foco deste artigo está centrado nos anos anteriores à crise não só em razão das restrições de dados, mas, também, porque a análise do impacto da crise atual nos processos de conexão às RPGs exigiria outro artigo.

Antes de 2014, o setor de petróleo e gás no Brasil tinha uma história de sucesso. De fato, o número de empresas deste setor aumentou consideravelmente durante a década de 2000 , particularmente durante a segunda metade desta década, ou seja, após as descobertas dos importantes recursos offshore. Por outro lado, o ano de 2010, conforme os dados da RAIS (ver Figura 4), marcou o início de uma certa paralisia no setor, em que a alteração no número de empresas, a partir de então, é insignificante. Especificamente em relação à geração de postos de trabalho no setor de petróleo e gás para o mesmo período, o que se pode verificar é que houve um aumento expressivo do número de empregos, especialmente de 2006 em diante (ver Figura 5). Entretanto, cumpre notar que a paralisia, visível no tocante ao número de empresas, é menos acentuada para o número de empregos.

Figura 4

Número de empresas do setor de petróleo e gás no Brasil

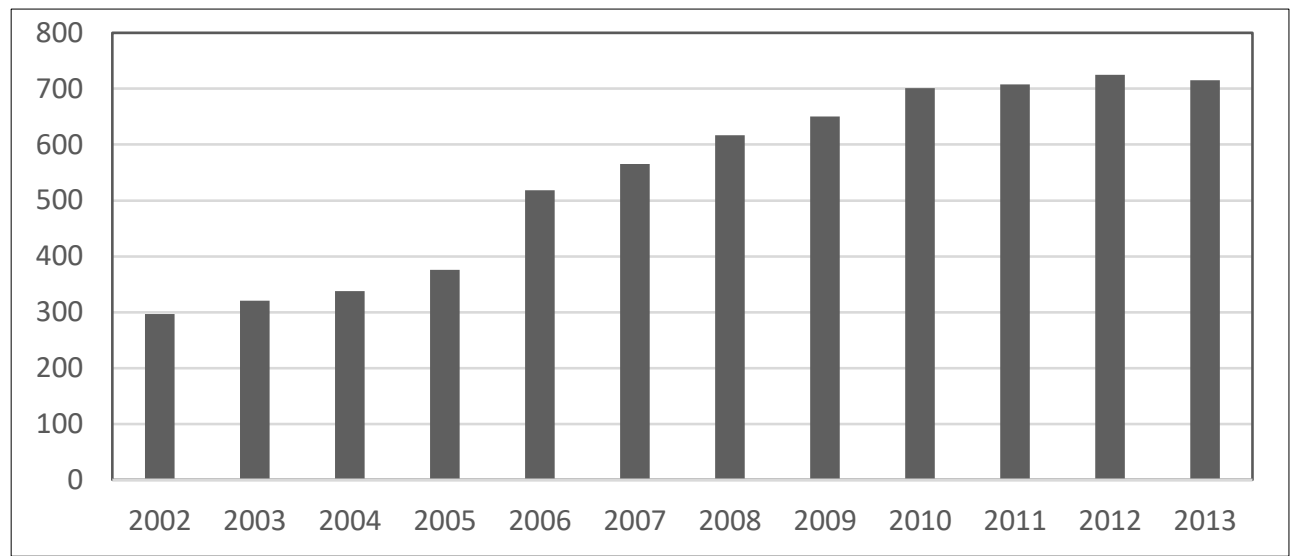

Obs.: A legislação brasileira determina que as empresas que desejam operar no setor de petróleo e gás possuam estabelecimentos no país. Os dados, portanto, incluem empresas nacionais e de origem estrangeira.

Fonte: Base de dados da RAIS-TEM (2014).

(12) O barril de óleo equivalente é uma unidade de energia baseada na energia aproximada liberada pela queima de um barril de petróleo bruto. É usado pelas empresas de petróleo e gás como forma de combinar produção de petróleo e gás natural e reservas em uma única medida. 
Figura 5

Número de empregos no setor de petróleo e gás no Brasil

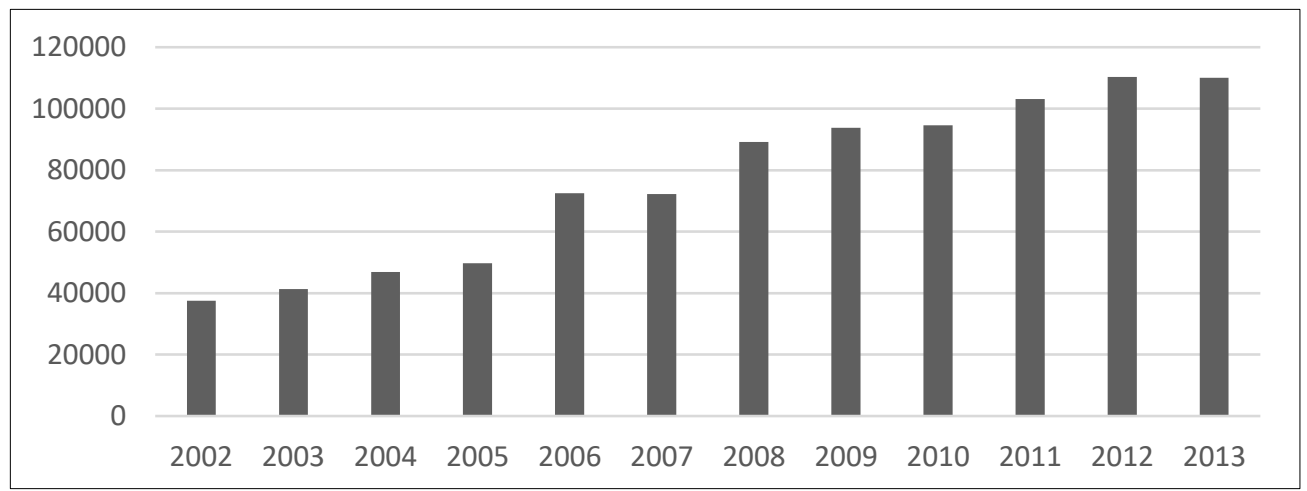

Fonte: Base de dados da RAIS-TEM (2014).

As atividades de petróleo e gás no Brasil são, de uma perspectiva espacial, altamente concentradas. Os sete Estados da federação mais importantes - Bahia, Espírito Santo, Minas Gerais, Rio Grande do Norte, Rio de Janeiro, São Paulo e Sergipe - representavam 77,8\% de todas as empresas do setor em 2013. Mais de 30\% dessas atividades estavam sediadas no Rio de Janeiro. A participação correspondente de São Paulo aumentou de 10,6\%, em 2003, para 17,5\%, em 2013. Os demais Estados tiveram um papel secundário. Os dados sobre o emprego revelam ainda mais claramente que o Rio de Janeiro é o polo do setor de petróleo e gás no Brasil, uma vez que respondia, em 2003, por 57,6\% e, em 2013, por 58\% de todos os empregos nesse setor. Já São Paulo foi responsável por 8,5\% e 11\%, respectivamente. No tocante ao emprego, o Estado da Bahia está num patamar mais próximo de São Paulo do que dos demais Estados secundários.

Torna-se importante ressaltar que os dados mencionados anteriormente apontam para dois aspectos fundamentais da dinâmica do setor de petróleo e gás após a descoberta das reservas do pré-sal: primeiro, o súbito crescimento até 2010, ano em que a curva estagna e sofre uma pequena inversão a partir do ano de 2013. Segundo, Rio de Janeiro e São Paulo ampliaram a diferença do número de empregos sobre os demais Estados. Dado o nível de agregação dos dados, não é possível concluir sobre como o Brasil se conectou às RPGs de petróleo e gás, daí a necessidade de se ter um olhar mais atento aos subsetores e à sua dinâmica. $\mathrm{O}$ banco de dados da RAIS classifica as empresas e os empregos de acordo com a Classificação Nacional de Atividades Econômicas (CNAE), que permite a divisão do setor de petróleo e gás nos seguintes ramos: exploração e extração; serviços de apoio à exploração e extração; processamento de petróleo e gás natural; e a produção de equipamentos utilizados para exploração e extração.

A comparação desses subsetores nos Estados federais acima mencionados revela que a exploração e extração, serviços de apoio e a produção de equipamentos para essas atividades têm um papel dominante no Rio de Janeiro. Já o processamento é predominante em São Paulo (ver Figuras 6 e 7). 
Figura 6

Empresas do setor de petróleo e gás por estado da federação e subsetor

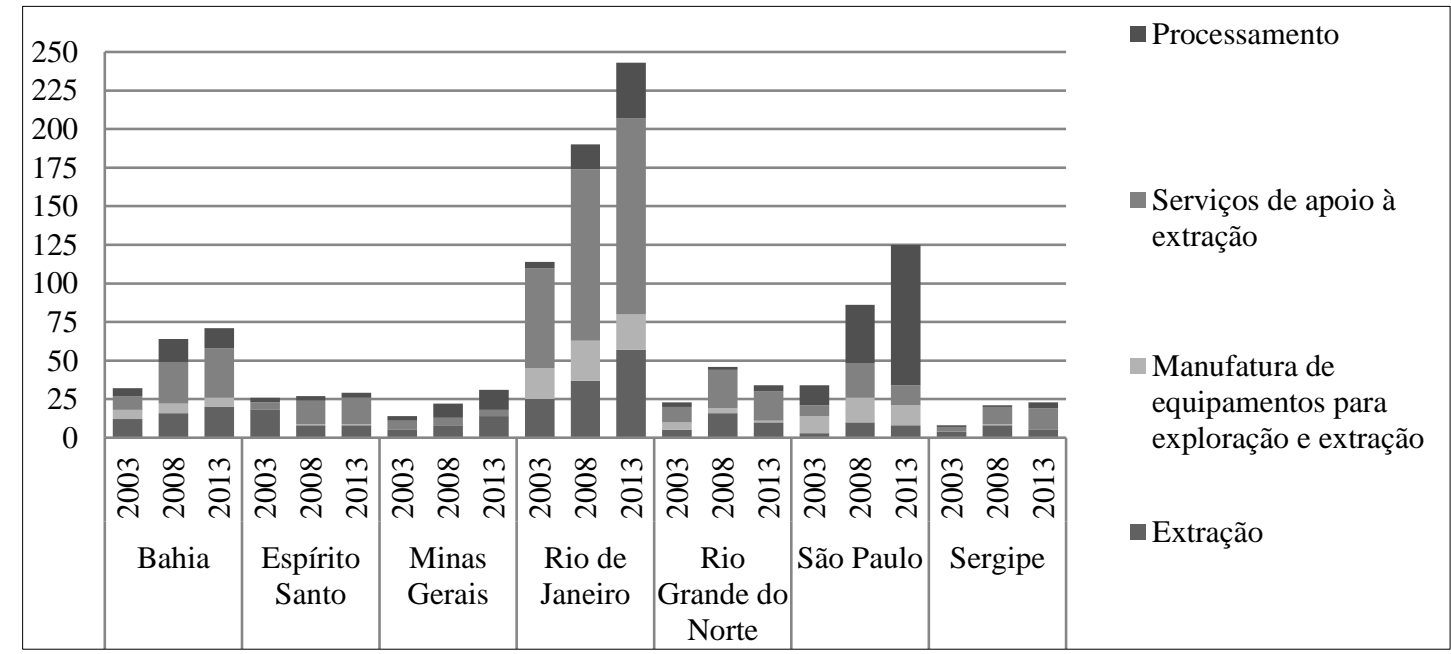

Fonte: Base de dados da RAIS-TEM (2014).

Figura 7

Empregos no Setor de Petróleo e Gás por Estado da Federação e Subsetor

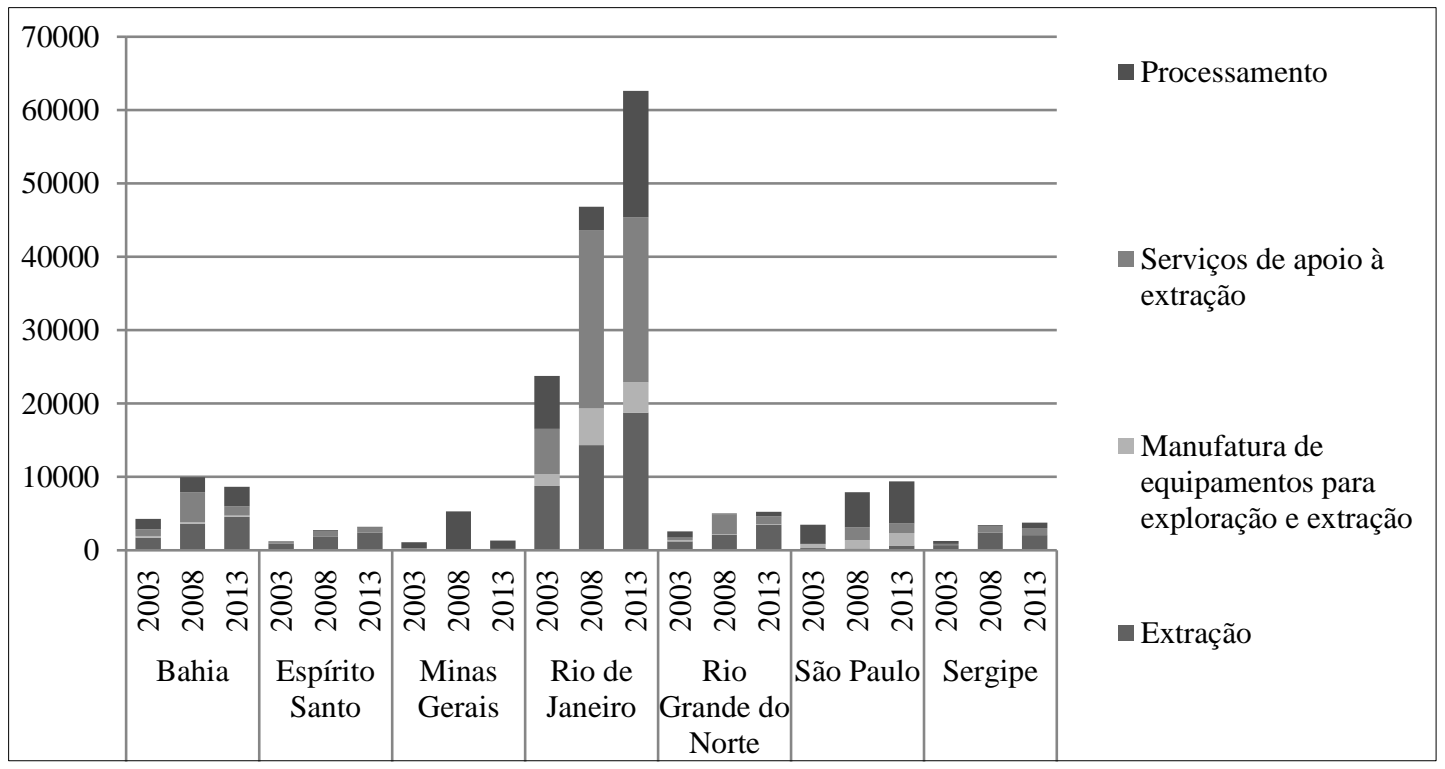

Obs.: Existem empregos em subsetores diferentes do processamento em Minas Gerais. Como o seu número é muito baixo, eles não são visíveis na figura.

Fonte: Base de dados da RAIS-TEM (2014).

O crescimento do setor que se observa em São Paulo se dá pelo crescimento do subsetor de processamento. O número de empresas envolvidas na exploração e na extração, bem como em serviços de suporte, diminuíram de 2008 a 2013, sendo importante sublinhar que esses 
subsetores representaram o crescimento geral do setor no Rio de Janeiro. Em outras palavras, Rio de Janeiro e São Paulo, dois dos Estados mais pujantes em termos econômicos da federação, desempenham papéis muito distintos nas RPGs de petróleo e gás. A distribuição de postos de trabalho por subsetor confirma que o papel dos sete Estados acima mencionados varia consideravelmente: o setor downstream domina em São Paulo, ao passo que o upstream no Rio de Janeiro. O processamento se recuperou, de 2008 a 2013, no Rio de Janeiro, muito embora não tenha se aproximado das atividades upstream.

A importância do Rio de Janeiro como ponto de partida da RPG de petróleo e gás também é confirmada pela localização dos escritórios dos operadores dos campos de petróleo e gás brasileiros (ver Quadro 2). Quanto à prestação de serviços, o Rio de Janeiro, apesar de certa diversidade existente, continua a ser o polo, especialmente quando se trata da localização dos escritórios das empresas (ver Tabela 1). Embora incompletos, os dados mostram que, além da cidade do Rio de Janeiro, apenas São Paulo e as cidades de Aracruz (Espírito Santo), e Macaé e Niterói (Rio de Janeiro) aparecem como locais dos escritórios dos prestadores de serviços mais importantes.

Quadro 1

Locais de escritórios dos operadores no Brasil

\begin{tabular}{|c|c|c|}
\hline Operadora & Local do escritório principal & $\begin{array}{c}\mathrm{N}^{\circ} \text { de campos de petróleo e } \\
\text { gás no Brasil }\end{array}$ \\
\hline Petrobras (BR) & Rio de Janeiro & 22 \\
\hline Shell (NL) & Rio de Janeiro & 2 \\
\hline Chevron (EUA) & Rio de Janeiro & 2 \\
\hline BP (GB) & Rio de Janeiro & 2 \\
\hline BG Group (GB) & Rio de Janeiro & 1 \\
\hline ONGC (IN) & Rio de Janeiro & 1 \\
\hline Repsol (ES) & Rio de Janeiro & 1 \\
\hline Inpex/Sojitz (JP) & Rio de Janeiro & 1 \\
\hline Maersk (DK) & São Paulo & 1 \\
\hline Anadarko (EUA) & Rio de Janeiro & 1 \\
\hline Statoil (NO) & Rio de Janeiro & 1 \\
\hline Sinochem (CN) & Rio de Janeiro & 1 \\
\hline Ouro Preto (BR) & Rio de Janeiro & 39 \\
\hline QGEP (BR) & Rio de Janeiro & 1 \\
\hline Total de campos de petróleo e & & \\
\hline gás & & \\
\hline Fon & & \\
\hline
\end{tabular}

Fonte: Elaboração Própria com base nos bancos de dados da A Barrel Full e dos sites das empresas, que foram consultados para localizar suas sedes no Brasil. 
Quadro 2

Locais dos escritórios dos prestadores de serviços de petróleo e gás no Brasil

\begin{tabular}{|c|c|c|c|c|c|}
\hline $\begin{array}{l}\text { Prestadora de } \\
\text { serviços } \\
\text { especializados }\end{array}$ & $\begin{array}{l}\text { Local do } \\
\text { escritório }\end{array}$ & $\begin{array}{l}\mathrm{N}^{\circ} \text { de campos } \\
\text { de petróleo e } \\
\text { gás no Brasil }\end{array}$ & $\begin{array}{l}\text { Prestadora de } \\
\text { serviços } \\
\text { especializados }\end{array}$ & $\begin{array}{l}\text { Local do } \\
\text { escritório }\end{array}$ & $\begin{array}{l}\mathrm{N}^{\circ} \text { de campos } \\
\text { de petróleo e } \\
\text { gás no Brasil }\end{array}$ \\
\hline $\begin{array}{c}\text { FMC } \\
\text { Technologies } \\
\text { (EUA) }\end{array}$ & Rio de Janeiro & 10 & Nexans (FR) & Rio de Janeiro & 2 \\
\hline Modec (JP) & Rio de Janeiro & 6 & KBR (EUA) & Rio de Janeiro & 1 \\
\hline Technip (FR) & Rio de Janeiro & 5 & $\begin{array}{c}\text { Wellstream } \\
\text { International } \\
(\mathrm{GB})\end{array}$ & $\begin{array}{l}\text { Niterói (Rio de } \\
\text { Janeiro) }\end{array}$ & 1 \\
\hline Saipem (IT) & Rio de Janeiro & 5 & PGS (NO) & Rio de Janeiro & 1 \\
\hline $\begin{array}{c}\text { Oceaneering } \\
\text { (EUA) }\end{array}$ & Rio de Janeiro & 4 & BrasFels (SG) & Rio de Janeiro & 1 \\
\hline Keppel (SG) & Rio de Janeiro & 4 & Inocean (NO) & $\begin{array}{c}\text { Sem escritório } \\
\text { no país }\end{array}$ & 1 \\
\hline $\begin{array}{c}\text { SBM Offshore } \\
(\mathrm{NL})\end{array}$ & Rio de Janeiro & 3 & Cosco (SG) & São Paulo & 1 \\
\hline Subsea 7 (GB) & Rio de Janeiro & 3 & Nessco (GB) & $\begin{array}{c}\text { Macaé (Rio de } \\
\text { Janeiro) }\end{array}$ & 1 \\
\hline $\begin{array}{c}\text { Jurong Shipyard } \\
\text { (SG) }\end{array}$ & $\begin{array}{c}\text { Aracruz } \\
\text { (Espírito } \\
\text { Santo) }\end{array}$ & 3 & $\begin{array}{l}\text { VME Process } \\
\text { (EUA) }\end{array}$ & Rio de Janeiro & 1 \\
\hline Aker (NO) & Rio de Janeiro & 3 & $\begin{array}{l}\text { Dril-Quip } \\
\text { (EUA) }\end{array}$ & $\begin{array}{c}\text { Macaé (Rio de } \\
\text { Janeiro) }\end{array}$ & 1 \\
\hline $\begin{array}{c}\text { Stolt Offshore } \\
\text { (GB) }\end{array}$ & São Paulo & 3 & $\begin{array}{c}\text { First Subsea } \\
\text { (GB) }\end{array}$ & $\begin{array}{c}\text { Sem escritório } \\
\text { no país }\end{array}$ & 1 \\
\hline $\begin{array}{c}\text { Intermoor } \\
\text { (EUA) }\end{array}$ & Rio de Janeiro & 2 & $\begin{array}{l}\text { IKM Ocean } \\
\text { Design (NO) }\end{array}$ & Rio de Janeiro & 1 \\
\hline Manatee (EUA) & $\begin{array}{c}\text { Sem escritório } \\
\text { no país }\end{array}$ & 2 & Vallourec (FR) & Rio de Janeiro & 1 \\
\hline Acergy (GB) & Rio de Janeiro & 2 & $\begin{array}{c}\text { Global } \\
\text { Industries } \\
\text { (EUA) }\end{array}$ & $\begin{array}{c}\text { Sem escritório } \\
\text { no país }\end{array}$ & 1 \\
\hline Fels Setal (SG) & $\begin{array}{l}\text { Niterói (Rio de } \\
\text { Janeiro) }\end{array}$ & 2 & $\begin{array}{c}\text { Damen } \\
\text { Shiprepair } \\
\text { Rotterdam (NL) }\end{array}$ & $\begin{array}{c}\text { Sem escritório } \\
\text { no país }\end{array}$ & 1 \\
\hline Mustang (EUA) & $\begin{array}{c}\text { Sem escritório } \\
\text { no país }\end{array}$ & 2 & Mitsui (JP) & São Paulo & 1 \\
\hline $\begin{array}{c}\text { McDermott } \\
\text { (EUA) }\end{array}$ & Rio de Janeiro & 2 & Tecna (IT) & Rio de Janeiro & 1 \\
\hline $\begin{array}{c}\text { FoundOcean } \\
\text { (GB) }\end{array}$ & $\begin{array}{c}\text { Sem escritório } \\
\text { no país }\end{array}$ & 2 & $\begin{array}{c}\text { Sembcorp } \\
\text { Marine (SG) }\end{array}$ & $\begin{array}{c}\text { Aracruz } \\
\text { (Espírito } \\
\text { Santo) }\end{array}$ & 1 \\
\hline
\end{tabular}

Fonte: Elaboração Própria com base nos bancos de dados da A Barrel Full e dos sites das empresas.

Obs.: Em virtude da sua incompletude, os dados sobre os prestadores de serviços mostram apenas uma tendência. 
Justifica esse panorama o fato de esse tipo de serviço ser não só marcado pelo casamento de uma elevada intensidade de capital e tecnologia com uma demanda altamente instável, como também dominado por poucas empresas globais. Esse cenário é diferente quando se observa as empresas prestadoras de serviço de segundo e terceiro níveis que, infelizmente, não são contempladas pela base de dados utilizada nesse artigo. Entretanto, isso indica que os serviços especializados em petróleo e gás no Brasil não atingiram o mesmo nível de sofisticação de outros países, tais como a Holanda, os Estados Unidos e a Noruega.

Esses fortes indícios estão em conformidade com o depoimento do diretor de uma empresa estrangeira de prestação de serviços upstream, que realçou haver muitos fornecedores locais subcontratados pelas empresas listadas no Quadro 2. Apesar de possuírem capacidades técnicas necessárias para o setor de petróleo e gás, esses fornecedores, conforme já ressaltado, não eram competitivos em razão das economias de escala num mercado altamente globalizado, o que fazia com que a sua integração nas RPGs dependesse da legislação de conteúdo local, sendo a consequência desse processo a pressão exercida nos fornecedores de primeira linha para estabelecer parcerias com empresas brasileiras. Convém ressaltar que o interesse das empresas estrangeiras de petróleo e gás pela política de conteúdo local residia no fato de que ela contribuía para a sustentabilidade dos seus empreendimentos no longo prazo. Essa estratégia, no entanto, foi seriamente abalada pela crise econômica, que acabou por impor a todos os atores, principalmente a Petrobras, a redução de custos como foco prioritário ${ }^{13}$.

Em seguida, uma análise dos chamados três Ds, complementando a abordagem RPG, é explorada objetivando melhor compreensão do envolvimento das empresas acima com o território.

\section{O impacto da densidade, distância e divisão}

Conforme mencionado anteriormente, Rio de Janeiro e São Paulo desempenham papéis muito diferentes nas RPGs de petróleo e gás. Apesar de São Paulo ser fundamental para o setor downstream, a sua relevância para o setor upstream é marginal, sendo importante destacar que a sede da Petrobras e o seu Centro de Pesquisas (CENPES) estão localizados no Rio de Janeiro. Cabe aqui sublinhar que é exatamente essa empresa líder que vincula todas as demais do setor a si. Um dos entrevistados, que trabalha como consultor privado e possui um profundo conhecimento das práticas da Petrobras, declarou que "todos os que trabalham com a Petrobras [em atividades upstream] precisam estar no Rio de Janeiro". Além disso, ele sublinhou o fato de que a Petrobras especifica em seus contratos com empresas estrangeiras que estas têm que abrir um escritório próximo da sua sede ${ }^{14}$.

Como consequência dessa divisão do setor entre as duas maiores cidades do Brasil, algumas empresas transnacionais como a Shell têm duas sedes no Brasil: as atividades

(13) Entrevista, realizada em Guarujá em 19 de abril de 2017, com um diretor local de uma empresa internacional de prestação de serviços upstream.

(14) Entrevista, realizada em São Paulo em 7 de maio de 2014, com um consultor de petróleo e gás. 
downstream são tratadas em São Paulo, enquanto as upstream são gerenciadas do Rio de Janeiro. No entanto, o entrevistado mencionado acima enfatizou que $60 \%$ dos insumos industriais exigidos pelo setor de petróleo e gás, tais como motores e tubos, são produzidos no Estado de São Paulo. Os entrevistados dos poderes públicos também mencionaram esse mesmo percentual, que resulta do fato de São Paulo ser o Estado mais industrializado do país ${ }^{15}$.

Esse percentual está aparentemente fundamentado em uma ampla compreensão dos insumos industriais. Os dados da RAIS mostrados acima sugerem que o Rio de Janeiro domina a fabricação de equipamentos para o setor de petróleo e gás. Entretanto, a maior parte dos insumos que os fabricantes precisam vem de São Paulo. As empresas, sediadas nesse Estado e produtoras desses insumos, atendem a numerosos setores, não estando os seus produtos limitados ao setor de petróleo e gás.

Apesar do setor upstream estar concentrado no Rio de Janeiro, o governo de São Paulo identificou oportunidades econômicas em setores, tais como engenharia marítima, logística e construção naval, tradicionalmente localizados no Estado vizinho. O estudo aponta para a previsão da criação de bases de abastecimento previstas para as cidades costeiras de Bertioga e São Sebastião (onde já se explora petróleo offshore) e serviços industriais para operações offshore a partir de Caraguatatuba, Itanhaém e Peruíbe, previstos, portanto, para receber investimentos de empresas nacionais e estrangeiras, sem esquecer que vários serviços não industriais - que variam desde alojamento até aluguel de carros para exposições - seriam beneficiados pelos desdobramentos do setor de petróleo e gás offshore ${ }^{16}$. Não obstante o reconhecimento de que o Rio de Janeiro é o polo tanto para os operadores dos campos de petróleo e gás quanto para os fornecedores de serviços de primeira linha, os representantes de organizações públicas responsáveis pela promoção do desenvolvimento econômico e do investimento em São Paulo expressaram a esperança de que a mudança da exploração offshore para o sul - isto é, da Bacia de Campos para a Bacia de Santos - desencadeasse a realocação de algumas atividades upstream, especialmente para o Porto de Santos ${ }^{17}$.

É exatamente em função do desenvolvimento das atividades de exploração na Bacia de Santos que foi ressaltado o fato de as empresas transnacionais, cujas sedes são (e permanecerão) no Rio de Janeiro, terem aberto, segundo o consultor entrevistado, "pequenos escritórios de representação" na cidade de Santos. Essa mudança de localização foi resultado de um movimento feito pela Petrobras, que abriu naquela cidade litorânea paulista um escritório de coordenação para a Bacia de Santos ${ }^{18}$. Embora essas novas bases oferecessem perspectivas de investimentos maciços, o que parece ter havido foi uma forte persistência de

\footnotetext{
(15) Entrevistas, realizadas em 30 de abril de 2014, com representantes da Secretaria Estadual de Energia do Estado de São Paulo.

(16) Apresentação realizada, em dezembro de 2010, para discussões internas do governo de São Paulo e fornecida aos autores.

(17) Entrevistas, realizadas em 28 e 30 de abril de 2014 respectivamente, com executivos da Investe São Paulo e da SP Business.

(18) Entrevista, realizada em São Paulo em 7 de maio de 2014, com um consultor do setor de petróleo e gás.
} 
padrões espaciais, isto porque a Petrobras preferiu concentrar, na medida do possível, suas atividades no Rio de Janeiro.

Somente uma enorme expansão das atividades na Bacia de Santos, de acordo com o entrevistado acima, poderia promover uma grande realocação do setor upstream. Mesmo nesse caso, o Rio de Janeiro e suas bases de abastecimento ainda estariam relativamente próximas da Bacia de Santos, o que reduziria os benefícios da realocação ${ }^{19}$. Portanto, a pequena distância e a divisão entre Rio de Janeiro e São Paulo sugerem um maior grau de complexidade nos processos de conexão em São Paulo. Outro fator a corroborar a dificuldade de realocação do setor upstream está no fato de que tanto o gerenciamento quanto o fornecimento de atividades na Bacia de Santos são relativamente fáceis de serem operados das sedes existentes e das bases de abastecimento no Rio de Janeiro.

Independentemente dessas questões sobre a territorialidade das RPGs, a conexão das empresas brasileiras é facilitada pelo papel dominante da Petrobras. As empresas locais não precisam se associar diretamente aos investidores estrangeiros. Na verdade, elas podem se conectar às RPGs através dos laços que estabeleceram com a Petrobras, que usa um sistema on-line para certificar e registrar fornecedores. Este registro compreende fornecedores de mais de 4.000 tipos de equipamentos, variando desde caldeiras para permutadores de calor a painéis elétricos, e cerca de 2.500 tipos de serviços, tais como perfuração e manutenção. As empresas certificadas e registradas pela Petrobras podem entrar em seu banco de dados, que serve de orientação para as empresas contratadas, significando que elas podem escolher suas subcontratadas do banco de dados da Petrobras.

A condição de ser parte da base de dados da Petrobras não significa, no entanto, que uma empresa será convidada para cada processo de licitação. Na verdade, a Petrobras préseleciona os licitantes com base na proposta em questão. Além disso, é fundamental ter em mente que os serviços mais sofisticados no setor de petróleo e gás upstream são fornecidos por empresas transnacionais, tais como Baker Hughes, Halliburton e Schlumberger. Os serviços que essas empresas fornecem são altamente intensivos em conhecimento, de domínio restrito e, ao mesmo tempo, não são demandados com frequência. As empresas locais, além de não terem capacidade de resposta a estas demandas, também não estariam fazendo uma escolha racional ao se especializar para poder fornecer esses serviços: a capacidade de fornecer tais serviços implicaria consideráveis investimentos (em mão de obra qualificada, tecnologias, etc.) e responderia a uma demanda pequena e inconstante.

Enquanto a Petrobras reduz a divisão para fornecedores brasileiros, parece que ela a aumenta para os operadores estrangeiros. A estatal brasileira de petróleo, segundo uma consultora entrevistada, obteve os melhores blocos nas ofertas de concessão passadas, ao passo que as empresas estrangeiras obtiveram os mais pobres, sendo essas práticas responsáveis pelo desestímulo do investimento estrangeiro mesmo antes do declínio do preço do petróleo. Essa

(19) Entrevista, realizada em São Paulo em 7 de maio de 2014, com um consultor do setor de petróleo e gás. 
consultora ainda acrescentou que as oportunidades de investimento não resultam tanto da disponibilidade de recursos, mas sim das condições políticas que afetam os investimentos previstos, sendo esta a razão pela qual o México, entre outros países, com o seu setor de energia recentemente liberalizado, é mais atraente para os investidores estrangeiros do que o Brasil ${ }^{20}$, pelo menos antes das reformas da política de conteúdo local mencionadas acima.

O impacto da densidade, distância e divisão pode ser demonstrado pelos investimentos nos dois parques tecnológicos que se concentram no setor de petróleo e gás. Esses parques destinam-se a gerar inovação, facilitando as redes formais, principalmente aquelas que dependem da proximidade (Basile, 2011; Feldman, 1999). Em suma, eles atraem empresas envolvidas em pesquisa e desenvolvimento, criando densidade e superando a distância e a divisão. Um dos parques tecnológicos intrinsecamente ligado ao setor de petróleo e gás no Brasil está localizado na cidade do Rio de Janeiro, especificamente na Ilha do Fundão, onde se localiza, também, a Universidade Federal do Rio de Janeiro (UFRJ), ao passo que o outro fica em Santos, sendo a Petrobras a empresa âncora em ambos ${ }^{21}$.

Conforme mencionado anteriormente, pelo menos o parque tecnológico do Rio de Janeiro serve como porta de entrada, permitindo que as empresas estrangeiras gerem conhecimento e se adaptem às tecnologias existentes e às condições locais, ou seja, às exigências específicas do pré-sal, em que a exploração é realizada em águas ultra-profundas. Elas, na maioria das vezes, associam-se às empresas brasileiras para esse propósito, ampliando, assim, os efeitos de difusão de conhecimento e inovação. Os parques tecnológicos podem, também, constituir-se em trampolins para as empresas brasileiras se internacionalizarem, promovendo tecnologias desenvolvidas inicialmente para aplicações locais e que podem ter alcance global.

Concomitantemente à criação de infraestrutura, a legislação nacional deu um certo impulso às atividades de pesquisa relacionadas ao petróleo e gás. O arcabouço regulatório para a extração de petróleo nos principais campos exige que todas as empresas envolvidas nesses campos, fundamentalmente a Petrobras, invistam pelo menos $1 \%$ de suas receitas brutas em pesquisa e desenvolvimento. A metade desses recursos deve ser utilizada para a contratação de instituições de pesquisa locais, principalmente as universidades públicas, podendo a outra metade ser usada internamente ou na terceirização (ANP, Resolução n. 33 de 2005). Essa política reflete o apoio do governo aos esforços da Petrobras em ampliar o seu papel como líder tecnológico através da cooperação com empresas parceiras nacionais e estrangeiros em parques tecnológicos (MCTIC, 2016).

(20) Entrevista, realizada em São Paulo em 24 de agosto de 2015, com uma executiva de uma empresa de consultoria internacional.

(21) As informações sobre esses parques estão disponíveis nos sites www.fpts.org.br e www.parque.ufrj.br. 
Tabela 1

Investimento em P\&D da Petrobras e de Outras Empresas, 2003 a 2016

\begin{tabular}{c|c|c}
\hline & Petrobras & Outras Empresas \\
\hline 2003 & $323,299,906$ & - \\
\hline 2004 & $392,585,953$ & $11,117,686$ \\
\hline 2005 & $506,529,318$ & $2,279,136$ \\
\hline 2006 & $613,841,421$ & $2,547,915$ \\
\hline 2007 & $610,244,146$ & $6,259,121$ \\
\hline 2008 & $853,726,089$ & $7,132,144$ \\
\hline 2009 & $633,024,264$ & $5,858,020$ \\
\hline 2010 & $735,337,136$ & $11,579,885$ \\
\hline 2011 & $990,480,683$ & $41,416,212$ \\
\hline 2012 & $1,148,763,766$ & $77,922,925$ \\
\hline 2013 & $1,161,786,262$ & $98,080,695$ \\
\hline 2014 & $1,246,469,446$ & $161,095,785$ \\
\hline 2015 & $894,001,057$ & $136,955,340$ \\
\hline 2016 & $456,362,515$ & $98,070,311$ \\
\hline
\end{tabular}

Fonte: ANP (vários anos).

O parque tecnológico do Rio de Janeiro data de 1963, quando o Instituto Alberto Luiz Coimbra de Pós-Graduação e Pesquisa de Engenharia (COPPE) foi criado, na Ilha do Fundão, pela Universidade Federal do Rio de Janeiro (UFRJ). A Petrobras, dez anos depois, fundou, nas cercanias do parque, o CENPES, um centro de pesquisas e desenvolvimento direcionado para o setor de petróleo e gás. Pode-se considerar que o CENPES foi a primeira grande parceria universidade-indústria na história do país, servindo de pontapé inicial para inúmeros projetos de pesquisa realizados por pesquisadores da UFRJ. O próprio parque tecnológico só foi aprovado pelo conselho da UFRJ em 1997 e as autoridades municipais do Rio de Janeiro lançaram, três anos mais tarde, um projeto de infraestrutura urbana.

Foram necessários mais três anos até que o primeiro laboratório de pesquisa em tecnologia oceânica iniciasse os seus trabalhos. Outros laboratórios mantidos pela COPPE realizam pesquisas sobre tecnologias para o setor de gás natural, desenvolvem métodos numéricos em mecânica computacional, testam vários produtos utilizados no setor de petróleo e trabalham na recuperação de ecossistemas. Entretanto, torna-se importante sublinhar que o dinamismo do parque tecnológico do Rio de Janeiro ocorreu somente após a descoberta dos recursos do pré-sal e a intensa pressão da Petrobras sobre os seus parceiros estrangeiros ${ }^{22}$. Entrevistas realizadas por Rocha e Urraca-Ruiz (2012) confirmam que a grande quantidade de

(22) Entrevista, realizada no Rio de Janeiro em 12 de dezembro de 2016, com um representante do parque tecnológico do Rio de Janeiro. 
reservas offshore tem sido o principal motivo para as empresas estrangeiras se instalarem no parque, que conta hoje com um total de 57 escritórios de empresas, incluindo 27 start-ups.

O parque tecnológico do Rio de Janeiro, para as empresas estrangeiras, não serve apenas como uma porta de entrada para o Brasil e os seus recursos offshore. De fato, empresas como a Baker Hughes e a Schlumberger manifestaram nas entrevistas com Rocha e UrracaRuiz que elas procuram aprender a respeito da exploração do pré-sal e das condições de produção porque estão cientes de que o conhecimento desenvolvido no Brasil poderá ser utilizado em outros lugares. Por sua vez, a FMC Technologies concentra-se na adaptação de suas tecnologias às necessidades da Petrobras, que a contratou para várias operações. Portanto, enquanto a FMC Technologies está explorando seus ativos existentes através da adaptação, a Baker Hughes e a Schlumberger procuram aumentar os seus absorvendo tecnologias brasileiras e desenvolvendo outras em parceria com empresas nacionais.

Em 2011, o parque tecnológico de Santos foi lançado oficialmente, sendo, portanto, um projeto bem mais recente do que o do Rio de Janeiro. Ele foi inaugurado no contexto da exploração de novos campos de petróleo e gás ao largo da costa da cidade. Representantes governamentais expressaram grandes esperanças no desenvolvimento do parque, em especial no que se refere às atividades de pesquisa realizadas conjuntamente pela Petrobras e as universidades do Estado de São Paulo ${ }^{23}$. No entanto, o Parque de Santos não se limita somente ao setor de petróleo e gás, posto que ele abrange outras áreas, tais como comunicação e tecnologia da informação, logística portuária, energia renovável e desenvolvimento urbano, que não deixam de ter, pelo menos aparentemente, conexões com o setor de petróleo e gás.

O objetivo geral é fortalecer a competitividade das empresas locais e suas capacidades inovadoras, reunindo-as com parceiros não-locais, instituições educacionais e universidades. Atualmente, muitas empresas locais não podem, no entanto, superar o problema da divisão e, portanto, não conseguem se conectar às RPGs de petróleo e gás. Segundo o referido representante do governo municipal de Santos, as empresas locais têm frequentemente as habilidades técnicas necessárias para participar do setor, mas não são muito profissionais em termos de gestão. Além disso, as barreiras linguísticas também dificultam a colaboração entre empresas locais e estrangeiras. É interessante notar que esse representante governamental ressaltou que o governo municipal apoia o setor organizando eventos que tem por objetivo reunir investidores estrangeiros e empresas locais. Ademais, a cidade oferece espaço de escritório no parque tecnológico às empresas de petróleo e gás, as quais, também, beneficiamse dos incentivos fiscais.

Outro aspecto importante sublinhado pelo referido representante é a necessidade de se qualificar o empresariado e a mão-de-obra locais. Entretanto, essa questão não é consensual na medida em que representantes da Comissão Especial de Petróleo e Gás do Estado de São Paulo (CESPEG) não a consideram prioritária, uma vez que muito mais tem de ser feito para

(23) Entrevistas, realizadas em 30 de abril de 2014 e 18 de agosto de 2015 respectivamente, com representantes da Secretaria Estadual de Energia de São Paulo e do Município de Santos. 
identificar as tecnologias que os fornecedores independentes necessitam e, ao mesmo tempo, estimular as pesquisas correspondentes. Antes da crise doméstica, a CESPEG (2010) havia identificado alguns setores em que pesquisas específicas poderiam ser realizadas pelas instituições locais. Dentre esses setores, estão a captura e o armazenamento de carbono, diferentes formas de engenharia (especialmente para operações submarinas, mas também para uso do gás natural que é liberado ao se explorar recursos de petróleo offshore), pesquisas geológicas e logística especializada.

A área destinada para o parque tecnológico de Santos ainda está em construção, mas várias parcerias, muitas das quais impulsionadas pelas universidades que lá planejam abrir seus laboratórios, já foram estabelecidas. Está previsto que as grandes empresas brasileiras - como é o caso da Usiminas -, e as organizações empresariais locais e nacionais, também estarão no Parque, sendo as mais importantes: a Associação Comercial de Santos, a Federação das Indústrias do Estado de São Paulo e o Serviço Brasileiro de Apoio às Micro e Pequenas Empresas. De salientar ainda, que a Petrobras se comprometeu a investir num centro de tecnologia de petróleo e gás em Santos: o Centro Tecnológico da Baixada Santista (CTBS), cujo objetivo é explorar ainda mais os recursos offshore próximos. Para tanto, as universidades paulistas com excelência em pesquisa - a Universidade Estadual de Campinas, a Universidade Estadual Paulista e a Universidade de São Paulo - colaborarão diretamente com o CTBS.

\section{As RPGs e o setor brasileiro de petróleo e gás}

Nesta seção, as informações empíricas, acima mencionadas, são apresentadas juntamente com a abordagem da RPG, em que são ressaltadas tanto as descobertas da pesquisa quanto as questões que requerem mais análises empíricas. Ficou claro que o setor brasileiro de petróleo e gás, especialmente seus componentes upstream, está concentrado no Rio de Janeiro, onde a empresa líder do setor está localizada: a Petrobras. São Paulo é o segundo Estado da federação mais importante, sendo essa relevância resultado principalmente do processamento, ou seja, das atividades dowstream, que muito provavelmente estão relacionadas ao grande mercado local. Em suma, o envolvimento territorial da RPG de petróleo e gás no Brasil varia consideravelmente de um Estado da federação para outro.

Além do mais, o Rio de Janeiro serve como uma porta de entrada em escala nacional. Conforme apontado acima, da mesma forma que a Petrobras tem a sua sede nesta cidade, todos os outros operadores de campos de petróleo nela estabeleceram os seus escritórios. Embora os dados sobre os prestadores de serviços estejam incompletos, eles sugerem claramente que o Rio de Janeiro serve como um polo para essas empresas. Pelo menos no caso do parque tecnológico do Rio de Janeiro, o papel de porta de entrada foi facilitado pelas instituições, uma vez que o parque não só foi criado pelas autoridades públicas para facilitar a cooperação das empresas locais e estrangeiras, como também se baseou na colaboração de longo prazo entre a Petrobras e a UFRJ.

Convém ressaltar que a Petrobras, além de moldar as interligações territoriais do setor de petróleo e gás, é, igualmente, crucial para a criação, o aprimoramento e a captura de valor. De fato, a Petrobras cria valor, sendo o extrator de petróleo e gás mais importante do país. A 
sua criação de valor resulta de diferentes formas de renda: a tecnológica, pela sua liderança e domínio da tecnologia; a de recursos, uma vez que dado seu domínio tecnológico e a regulação existente é a empresa que usufrui do acesso ao petróleo e gás brasileiros; e política, pois como a principal empresa nacional é capaz de influenciar a agenda política em seu favor, mas é, ao mesmo tempo, usada pelo Estado como importante suporte de políticas públicas (ver Quadro 3). A Petrobras aumenta o valor por meio do refino de petróleo bruto e da purificação do gás natural bruto, além de capturar uma parcela considerável do valor gerado nas RPGs brasileiras de petróleo e gás.

É importante acrescentar que seu papel se estende ao setor downstream, onde desempenha um papel dominante, possuindo 15 refinarias que respondem por quase toda a produção nacional de petróleo refinado. Nesse sentido, o Brasil, em comparação com outras regiões do Sul Global, que geralmente desempenham um papel subordinado nas RPGs, conecta-se a estas redes de petróleo e gás através de uma empresa líder. Isso significa que o poder de decisão deste setor no país está, em grande medida, concentrado no Brasil e não no Norte Global. Como a internacionalização da Petrobras no início da década de 1990 até o final da última década mostrou, a empresa é capaz de criar uma RPG própria (Scholvin et al., 2017).

A criação, o aumento e a captura de valor são fortemente influenciados pela legislação sobre o conteúdo local, não só pela Petrobras como, também, pelas suas fornecedoras. Neste quesito, é plausível afirmar que esta foi uma opção do governo brasileiro, que, dadas a situação de descoberta e dos preços internacionais praticados, até 2014, pôde decidir as condições de operação das empresas internacionais. Mostraram-se determinantes, portanto, o desempenho positivo da Petrobras na extração e refino de petróleo e os preços internacionais elevados do petróleo.

No entanto, a atual (e grave) crise da Petrobras, assim como o declínio do preço do petróleo, enfraqueceram a posição de barganha do governo e a obrigatoriedade de participação da Petrobras nos leilões acabou afastada legalmente. Estas mudanças recentes na política brasileira de conteúdo local, especialmente o fim da participação mínima de $30 \%$ da Petrobras, também podem ser atribuídas às políticas econômicas do atual governo, que diferem fundamentalmente daquelas implementadas pelos governos anteriores.

Quadro 3

Criação de valor através de renda

\begin{tabular}{|l|l|}
\hline \multicolumn{1}{|c|}{ Renda } & \multicolumn{1}{c|}{ Exemplos } \\
\hline Recursos & Petróleo e gás offshore \\
\hline Tecnologia & Liderança do pré-sal, operações em águas profundas \\
\hline Finanças & Não está claro \\
\hline Infraestruturas & Não está claro \\
\hline Organização & Parques tecnológicos \\
\hline Marca & Não está claro \\
\hline Política & Legislação sobre conteúdo local e participação nos leilões \\
\hline
\end{tabular}

Fonte: Elaboração própria. 
Independentemente de qual corrente política-ideológica molde a política econômica brasileira, o direito de preferência concedido à Petrobras até agora garantiu que esta gigante brasileira continue a desempenhar um papel chave nas RPGs, que abrangem os campos de petróleo e gás no Brasil. Mantém-se como cláusula que os investidores estrangeiros são, conforme mencionado anteriormente, obrigados a investir em atividades de pesquisa no país. Considerando a existência de enormes recursos offshore, dos desafios técnicos que se colocam para sua exploração e o fato de a Petrobras ser a empresa líder em tecnologias dessa área específica, é muito provável que houvesse um investimento significativo na pesquisa de petróleo e gás no Brasil, mesmo se o governo não tivesse aprovado a legislação que tornasse esse investimento obrigatório.

Do ponto de vista da conexão às RPGs, o resultado é mais importante do que a sua causalidade: as empresas brasileiras não só participam dos segmentos de extração e processamento da RPG de petróleo e gás, como também desempenham um papel - no caso da Petrobras, o de líder - em atividades de pesquisa. As atividades dessas empresas são, em termos funcionais, complexas na medida em que produzem para um mercado especializado, trabalham com tecnologias de desenvolvimento de produtos e processos de alta intensidade, e requerem uma força de trabalho qualificada. Isso aumenta a criação de valor e valorização no Rio de Janeiro e, potencialmente, também, em Santos.

Torna-se importante ressaltar que a ligação funcional somente se aplica às empresas brasileiras que se estabeleceram com sucesso no parque tecnológico do Rio de Janeiro. Além de seus produtos e serviços não serem padronizados, as empresas não se limitam necessariamente a participar de atividades realizadas no Brasil. As empresas nacionais com ligações funcionais possuem um potencial razoável para empregar as suas habilidades em outros lugares, usando o parque como um trampolim para a internacionalização de seus respectivos negócios. A própria Petrobras também estabelece ligações funcionais, pois é um parceiro crítico para investidores estrangeiros e desenvolve soluções completas para desafios logísticos, gerenciais e técnicos.

As empresas que se beneficiam da legislação de conteúdo local, mas não estão envolvidas em atividades de pesquisa, são exemplos típicos de ligação estrutural através de fornecedores genéricos, o que significa que elas fornecem produtos e serviços padronizados por exemplo, motores e canos - para as atividades realizadas em sua região. A resolução acima, mencionada pela ANP, garante que essas empresas participam das RPGs de petróleo e gás, ainda que com funções com intensidade tecnológica inferior.

Os impactos econômicos destas RPGs, que vão além da criação de empregos e da contribuição direta do setor para o produto interior bruto, incluem os encadeamentos para a frente e para trás de todas as empresas envolvidas no setor de petróleo e gás e, também, o aprimoramento da mão-de-obra e das empresas parceiras locais, particularmente dos operadores estrangeiros e empreiteiros. 
Densidade, distância, divisão e as redes de produção globais: o caso do setor brasileiro de petróleo e gás

\section{Conclusões e desafios}

O setor brasileiro de petróleo e gás experimentou um boom na segunda metade da década de 2000 devido aos novos recursos offshore, que propiciaram um aumento considerável do número de empresas e empregos neste setor. Entretanto, o Brasil participa das RPGs de petróleo e gás de uma forma atípica, quando comparado aos países do Sul Global, sendo importante salientar que ele não possui apenas tremendos recursos minerais. A Petrobras é um importante jogador global, principalmente por sua liderança tecnológica nas operações em águas ultra-profundas do pré-sal.

As leis sobre conteúdo local, amplificadas de maneira considerável pelos governos do PT, e que refletem o conceito de desenvolvimentismo, garantem que o valor seja capturado localmente pela Petrobras e por muitas outras empresas brasileiras. Muitas dessas são fornecedores genéricos, envolvidos em processos de ligação estrutural. Algumas, incluindo a Petrobras, também têm ligações funcionais, particularmente nas partes intensivas em conhecimento das RPGs de petróleo e gás. Ao mesmo tempo, existem consideráveis diferenças territoriais nas RPGs de petróleo e gás no Brasil: enquanto o Rio de Janeiro é o polo do setor upstream, o setor downstream se concentra em São Paulo. Outros Estados da federação desempenham um papel muito menos importante do que o Rio de Janeiro e São Paulo.

Além do mais, os dados obtidos sugerem que a densidade faz com que o Rio de Janeiro seja uma porta de entrada, uma vez que ele não é apenas o polo para operadores e empreiteiros, mas também hospeda o Parque Tecnológico do Rio de Janeiro, onde as empresas supostamente se beneficiam da densidade. Especificamente em relação aos principais fornecedores de serviços estrangeiros, há uma clara percepção de que eles usam o Parque para obter acesso aos mercados e tecnologias brasileiras.

Os esforços para conectar Santos às RPGs de petróleo e gás revelam como a divisão entre investidores estrangeiros, de um lado, e empresas locais, do outro, impede os processos de conexão. Contrariamente, a pequena distância e a divisão em escala nacional dificultam a conexão do Estado de São Paulo e reforçam o papel do Rio de Janeiro como polo, pelo menos no que se refere ao setor upstream: a Bacia de Santos pode ser suprida do Rio de Janeiro e a transferência para Santos e outras cidades continua limitada.

Essa descoberta leva a uma primeira lacuna, ou talvez a um desafio, do conceito analítico que foi desenvolvido e aplicado nesse artigo. O Relatório de Desenvolvimento Mundial prevê eufemisticamente que a superação da distância e da divisão eventualmente leva ao desenvolvimento econômico em todos os lugares. No entanto, conforme já mencionado, tudo indica que o Rio de Janeiro continuará sendo o polo com poucos impactos positivos gerados para cidades costeiras paulistas. Esta descoberta frustrante está relacionada a uma contradição entre a teoria de Krugman (1991a; 1991b; 1992) e o Relatório de Desenvolvimento Mundial de 2009, em que o primeiro sugere que os baixos custos de transporte tendem a reforçar a polarização entre os polos, por um lado, e o seu interior, por outro. Com relação a isso, o desenvolvimento dos recursos de petróleo e gás no Norte e Nordeste do Brasil poderia 
desencadear dinâmicas econômicas regionais em função da considerável distância e divisão existente entre elas e o Rio de Janeiro. Para isso, as empresas de petróleo e gás cujas sedes estão no Rio de Janeiro terão, necessariamente, que abrir escritórios em cidades como Manaus e Recife, e buscar parceiros localizados nestas capitais ${ }^{24}$.

Em virtude de significativas disparidades espaciais terem sido apresentadas em escala subnacional, seria importante compreender essa dinâmica nas regiões mais periféricas do país. Embora o consumo se concentre em São Paulo e a maior parte dos recursos esteja localizada nas costas do Rio de Janeiro e de São Paulo, existem outras regiões que têm um potencial considerável para o setor de petróleo e gás, especialmente o Norte e o Nordeste. No que tange às disparidades espaciais e ao papel das cidades consideradas portas de entrada, é essencial analisar se as dinâmicas nas regiões centrais brasileiras geram efeitos propulsores em outras regiões, o que significa que haveria uma crescente transferência dos segmentos das RPGs para outras localidades além do Rio de Janeiro e São Paulo.

Além disso, poder-se-ia analisar que papel as diferentes regiões nos Estados do Rio de Janeiro e de São Paulo desempenham no processo de desenvolvimento do setor petróleo e gás com o claro propósito de entender as fragmentações funcionais em pequena escala das RPGs. Desta forma, descobrir-se-ia se a incorporação do Brasil nas RPGs de petróleo e gás levaria ao que o Hein (2000) descreve como novas ilhas de uma economia do arquipélago mundial.

Um segundo desafio conceitual resulta da aplicação do conceito de densidade neste artigo. Conforme foi mostrado, os três Ds complementam a abordagem da RPG na medida em que eles permitem explicar por que as regiões não se conectam às RPGs ou o fazem apenas de forma parcial. No entanto, existem inconsistências em relação à fusão da abordagem RPG e dos três Ds, principalmente quando o foco é o papel das cidades que servem de porta de entrada. A densidade, tal como concebida no Relatório de Desenvolvimento Mundial de 2009, está baseada nas economias de escala. As cidades que servem de porta de entrada se beneficiam das economias de escala, aparentemente como polos para processamento industrial e logística, duas dimensões deste tipo de cidade que mal foram abordadas neste artigo.

Por outro lado, os parques tecnológicos implicam que as cidades que servem de porta de entrada dependem da interação social e do conhecimento tácito. Essa compreensão da densidade é característica da pesquisa sobre inovação e cidades mundiais (Parnreiter, 2015; Storper, 1995; 1997) que está, no entanto, além do alcance dos três Ds, pelo menos em termos de seus antecedentes conceituais. Consequentemente, além das lacunas empíricas já mencionadas, as futuras pesquisas baseadas neste artigo poderão se beneficiar de uma elaboração mais aprofundada sobre o contexto em que os conceitos analíticos foram aqui aplicados para melhor integrá-los e superar as inconsistências.

(24) Entrevista, realizada em 28 de abril de 2014, com um executivo da Investe São Paulo. 
Densidade, distância, divisão e as redes de produção globais: o caso do setor brasileiro de petróleo e gás

\section{Referências bibliográficas}

AMIN, A.; TOMANEY, J. The regional development potential of inward investment in the less favoured regions of the European Community. In: AMIN, A.; TOMANEY, J. (Ed.). Behind the myth of European Union: prospects for cohesion. New York: Routledge, 1995. p. $172-189$.

ANP (Agência Nacional do Petróleo, Gás Natural e Biocombustíveis). Edital de Licitações para a Outorga dos Contratos de Concessão das Atividades de Exploração, Desenvolvimento e Produção de Petróleo e Gás Natural. Quinta Rodada de Licitações, Rio de Janeiro: ANP, 2003.

ANP (Agência Nacional do Petróleo, Gás Natural e Biocombustíveis). Edital de Licitações para a Outorga dos Contratos de Concessão - Parte A, Disposições Aplicáveis às Atividades de Exploração, Desenvolvimento e Produção de Petróleo e Gás Natural em Blocos com Risco Exploratório, Sétima Rodada de Licitações. Rio de Janeiro: ANP, 2005.

ANP (Agência Nacional do Petróleo, Gás Natural e Biocombustíveis). Petróleo e Estado. Rio de Janeiro: ANP, 2015.

ANP (Agência Nacional do Petróleo, Gás Natural e Biocombustíveis). Oportunidades no Setor de Petróleo e Gás no Brasil: Ações em Curso e Rodadas de Licitações 2018-2019. Rio de Janeiro: ANP, 2018.

BASILE, A. Networking system and innovation outputs: the role of science and technology parks. International Journal of Business Management, v. 6, n. 5, p. 3-14, 2011.

BICALHO, R. et al. Perspectivas do investimento em energia. 2009. Disponível em: http://www.ie.ufrj.br/projetopib/arquivos/01_ds_energia_petroleo.pdf.

BRESSER-PEREIRA, L. C. From old to new developmentalism in Latin America. In: OCAMPO, J. A.; ROSS, J. (Org.). The Oxford Handbook of Latin American Economics. Oxford: Oxford University Press, 2011. p.108-129.

CATTANEO, O.; GEREFFI, G.; STARITZ, C. Global value chains in a postcrisis world: resilience, consolidation, and shifting end markets. In: CATTANEO, O.; GEREFFI, G.; STARITZ, C. (Org.). Global value chains in a postcrisis world: a development perspective. Washington, D.C.: World Bank, 2010. p. 3-20.

COATES, D. (Org.). Varieties of capitalism, varieties of approaches. New York: Palgrave Macmillan, 2005.

COE, N. et al. Globalising' regional development: a global production networks perspective. Transactions of the Institute of British Geographers, v. 29, n. 4, p. 468-484, 2004.

COE, M.; DICKEN, P.; HESS, M. Global production networks: realizing the potential. Journal of Economic Geography, v. 8, n. 3, p. 271-295, 2008. 
Sören Scholvin, Maurício Serra, Mariane Françoso, Paula Bastos, Patrícia Mello, Adriano Borges

COE, N.; YEUNG, H. Global production networks: theorizing economic development in an interconnected world. Oxford: Oxford University Press, 2015.

COTTA, T. C.; PAIVA, L. H. O Programa Bolsa Família e a Proteção Social no Brasil”. In: CASTRO, J. A.; MODESTO, L. (Org.). Bolsa Família 2003-2010: avanços e desafios. Brasília: Ipea, 2010. p. 57-99.

DICKEN, P. The multi-plant enterprise and geographic space. Regional Studies, v. 10, n. 4, p. 401-412, 1976.

ERBER, F. Convenções de desenvolvimento no Brasil contemporâneo: um ensaio de economia política. 2010. Disponível em: http://repositorio.cepal.org/bitstream/handle/11362/28127/1/S2010940_pt.pdf.

ENERGY INFORMATION ADMINISTRATION. Brazil. 2016. Disponível em: https://www.eia.gov/beta/international/analysis includes/countries long/Brazil/brazil.pdf.

FELDMAN, M. The new economics of innovation, spillovers and agglomeration: a review of empirical studies. Economics of Innovation and New Technology, v. 8, n. 1-2, p. 5-25, 1999.

FIRN, J. R. External control and regional development: the case of Scotland. Environment and Planning A, v. 7, n. 4, p. 393-414, 1975.

FRASSA, J. et al. El rol estatal en sectores estratégicos: la industria naval pesada en Argentina y Brasil. Revista de Historia Industrial, v. 20, n. 3, p. 151-181, 2011.

GARCIA RIBEIRO, C.; FURTADO, A. T. Government procurement policy in developing countries: the case of Petrobras. Science Technology \& Society, v. 19, n. 2, p. 161-197, 2014.

GARCIA RIBEIRO, C.; TAHAN NOVAES, H. Petrobras 60 años: avances y retrocesos en el desarrollismo brasileño. América Latina Hoy, v. 72, p. 41-58, 2016.

GUDYNAS, E. Diez tesis urgentes sobre el nuevo extractivismo: contextos y demandas bajo el progresismo sudamericano actual. In: SCHULDT, J. et al. (Org.). Extractivismo, política y sociedad. Quito: Centro Andino de Acción Popular, 2009. p. 187-225.

GUDYNAS, E. Der neue progressive Extraktivismus in Südamerika. In: Forschungs-und Dokumentationszentrum Chile-Lateinamerika and Rosa Luxemburg Stiftung (Org.). Der Neue Extraktivismus: Eine Debatte über die Grenzen des Rohstoffmodells in Lateinamerika, Berlin: Forschungs- und Dokumentationszentrum. Chile: Lateinamerika, 2012. p. 46-62.

HALL, P. A.; SOSKICE, D. Varieties of capitalism: the institutional foundations of comparative advantage. Oxford: Oxford University Press, 2001.

HEIN, W. Die Ökonomie des Archipels und das versunkene Land. E+Z, v. 41, n. 11, p. 304$307,2000$.

HENDERSON, J. et al. Global production networks and the analysis of economic development. Review of International Political Economy, v. 9, n. 3, p. 436-464, 2002. 
Densidade, distância, divisão e as redes de produção globais: o caso do setor brasileiro de petróleo e gás

HESS, M. Spatial relationships?: Towards a reconceptualisation of embeddedness. Progress in Human Geography, v. 28, n. 2, p. 165-186, 2004.

HORNER, R. Strategic decoupling, recoupling and global production networks: India's pharmaceutical industry. Journal of Economic Geography, v. 14, n. 6, p. 1117-1140, 2014.

IPEA. Ipeadata. 2017. Disponível em: www.ipea.gov.br.

KAPLINSKY, R. Globalisation, industrialisation and sustainable growth: the pursuit of the nth rent. UK: Institute of Development Studies, 1998. (IDS Discussion Paper, n. 365).

KAPLINSKY, R. Globalization, poverty and inequality. Cambridge: Polity, 2005.

KRUGMAN, P. Geography and trade. Cambridge: MIT Press, 1991a.

KRUGMAN, P. Increasing returns and economic geography. Journal of Political Economy, v. 99, n. 3, p. 483-499, 1991 b.

KRUGMAN, P. A dynamic spatial model. 1992. (NBER Working Paper, n. 4219).

MARTIN, R.; SUNLEY, P. Paul Krugman's geographical economics and its implications for regional development theory: a critical assessment. Economic Geography, v. 72, n. 3, p. 259292, 1996.

MORAIS, J. M. Petróleo em águas profundas: uma história tecnológica da Petrobras na exploração e produção offshore. Brasília: Instituto de Pesquisa Econômica Aplicada, 2013.

MINISTÉRIO DA CIÊNCIA, TECNOLOGIA, INOVAÇÃO E COMUNICAÇÕES (MCTIC). Estratégia nacional de ciência, tecnologia e inovação 2016-2019. Brasília: MCTIC, 2016.

MURPHY, J. T.; SCHINDLER, S. Globalizing development in Bolivia?: Alternative networks and value-capture challenges in the wood products industry. Journal of Economic Geography, v. 11, n. 1, p. 61-85, 2011.

OCDE/CEPAL. Perspectivas económicas de América Latina 2012: transformación del Estado para el desarrollo. Paris: OECD Publishing, 2011.

PARNREITER, C. Managing and governing commodity chains: the role of producer service firms in the secondary global city of Hamburg. Die Erde, v. 146, n. 1, p. 1-15, 2015.

PETROBRAS. Relatório da administração 2014. 2015. Disponível em: http://www.investidorpetrobras.com.br/pt/relatorios-anuais/relatorio-de-administracao.

PETROBRAS. Relatório da administração 2015. 2016a. Disponível em: http://www.investidorpetrobras.com.br/pt/relatorios-anuais/relatorio-de-administracao.

PETROBRAS. Relatório estratégico: plano de negócios e gestão 2017-2021. 2016b. Disponível em: http://www.petrobras.com.br/pt/quem-somos/estrategia/plano-de-negocios-egestao. 
Sören Scholvin, Maurício Serra, Mariane Françoso, Paula Bastos, Patrícia Mello, Adriano Borges

PHELPS, N. A.; FULLER, C. Multinationals, intracorporate competition and regional development. Economic Geography, v. 76, n. 3, p. 224-243, 2000.

PHELPS, N. A. et al. Embedding the multinationals?: institutions and the development of overseas manufacturing affiliates in wales and North East England. Regional Studies, v. 37, n. 1 , p. $27-40,2003$.

PIKE, A. Making performance plants from branch plants?: in-situ restructuring in the automobile industry in the UK Region. Environment and Planning A, v. 30, n. 5, p. 881-900, 1998.

PINAR ERDEM, F.; ÜNALMIS, I. Revisiting super-cycles in commodity prices. Central Bank Review, v. 16, n. 4, p. 137-142, 2016.

PRESIDÊNCIA DA REPÚBLICA. Entenda a nova política para o setor de óleo e gás brasileiro. 2017. Disponível em: http://www2.planalto.gov.br/acompanheplanalto/noticias/2017/02/entenda-a-nova-politica-para-o-setor-de-oleo-e-gas-brasileiro.

RAINES, P. Flows and territories: the new geography of competition for mobile investment in Europe. In: PHELPS, N. A.; RAINES P. (Org.). The new competition for inward investment: Companies, institutions and territorial development. Cheltenham: Edward Elgar, 2003. p. 119137.

RIBEIRO CAHEN, F. Internationalization of state-owned enterprises through foreign direct investment. Revista de Administração de Empresas, v. 55, n. 6, p. 645-659, 2015.

ROCHA, F.; URRACA RUIZ, A. The role of the network coordinator in the attraction of foreign investment in R\&D: the case of the Brazilian oil and gas industry. Transnational Corporations, v. 20, n. 3, p. 33-60, 2012.

RODRÍGUEZ-POSE, A. Economic geographers and the limelight: the reaction to the 2009 World Development Report. Economic Geography, v. 86, n. 4, p. 361-370, 2010.

SANTOS, R. J.; AVELLAR, A. P. M. Políticas de apoio à indústria de petróleo e gás no Brasil: um estudo das ações públicas para o desenvolvimento da cadeia de valor. Economia $e$ Sociedade, v. 26, n. 3, p. 721-750, 2017.

SCHOLVIN, S. Cape town as a gateway city: interlinking the sub-saharan oil and gas sector globally. In: HARTZENBERG, T.; ERASMUS, G. (Org.). Monitoring regional integration in Southern Africa 2015/2016. Stellenbosch: Tralac, 2017. p. 128-181.

SCHOLVIN, S.; MALAMUD, A. Is there a geoeconomic node in South America?: Geography, politics and Brazil's role in regional economic integration. 2014. (ICS Working Paper, n. 2).

SCHOLVIN, S. et al. Gateway cities in global production networks: exemplified by the oil and gas sector. Campinas: IE/Unicamp, 2017. (Texto para Discussão, n. 307). 
SCHUTTE, G. R. Brasil: nuevo desarrollismo y petróleo de aguas profundas. Nueva Sociedad, n. 244, p. 122-133, 2013.

SERRANI, E. América Latina y su política petrolera frente a las últimas tendencias internacionales: perspectivas regionales a partir del análisis de Brasil y Argentina. Foro Internacional, v. 53, n. 1, p. 182-213, 2013.

SICSÚ, J.; DE PAULA, L. F.; MICHEL, R. Por que novo-desenvolvimentismo? Revista de Economia Política, v. 27, n. 4, p. 507-524, 2007.

STORPER, M. The resurgence of regional economies ten years later: the region as a nexus of untraded interdependencies. European Urban and Regional Studies, v. 2, n. 3, p. 191-221, 1995.

STORPER, M. The regional world: territorial development in a global economy. New York: Guilford, 1997.

SVAMPA, M. Resource extractivism and alternatives: Latin American perspectives on development. Journal für Entwicklungspolitik, v. 28, n. 3, p. 43-73, 2012.

TUROK, I. Inward investment and local linkages: how deeply embedded is silicon glen? Regional Studies, v. 27, n. 5, p. 401-417, 1993.

WATTS, H. D. The branch plant economy. London: Longman, 1981.

WORLD BANK. World Development Report: reshaping economic geography. Washington: World Bank, 2009.

WORLD BANK. Poverty and shared prosperity 2016: taking on inequality, Washington: World Bank, 2016.

YEUNG, H. W. Transnational corporations, global production networks and urban and regional development: a geographer's perspective on multinational enterprises and the global economy. Growth and Change, v. 40, n. 2, p. 197-226, 2009. 